\title{
Effects of Simultaneous Melatonin Administration on the Testis of the Experimentally Induced Hyper- and Hypothyroidism in the Adult Male Albino Rat
}

\section{Original Article}

\author{
Hala Z. E. Mohamed and Reneah R. Bushra \\ Department of Human Anatomy and Embryology, Faculty of Medicine, Assiut University, \\ Assiut, Egypt
}

\begin{abstract}
Background: The most common disorders of the thyroid gland are hyperthyroidism and hypothyroidism. Both have been linked to cell damage.

Aim of Work: This study was designed to evaluate the effect of melatonin administration on the testis of both hyperthyroidic and hypothyroidic adult male albino rats models.

Materials and Methods: Fifty adult male albino rats were used in this study and divided into five groups; ten rats each. Control group (G1) was given distilled water. Hyperthyroidic group (G2) was given thyroxin $(0.2 \mathrm{mg} / \mathrm{kg} \mathrm{b} . \mathrm{w})$. Hyperthyroidic + melatonin group (G3) was given thyroxin $(0.2 \mathrm{mg} / \mathrm{kg}$ b.w) and melatonin $(2.5 \mathrm{mg} / \mathrm{kg} \mathrm{b.w})$. Hypothyroidic group (G4) was given carbimazole (1.35 mg/kg b.w). Hypothyroidic+melatonin group (G5) was given carbimazole (1.35 mg/kg b.w) and melatonin $(2.5 \mathrm{mg} / \mathrm{kg} \mathrm{b.w})$. All the treatments were given orally for 15 days. At the end of the study, the animals of all groups were sacrificed and their testes were rapidly dissected out. The testicular mass was calculated. Testicular specimens of each group were processed for light and electron microscopic studies.

Results: The testicular mass was significantly decreased in both hyperthyroidic group (G2) and hypothyroidic group (G4) when compared with the control. Light and electron microscopy of the hyperthyroidic group (G2) and hypothyroidic group (G4) showed seminiferous tubular germ cells disorganization with increased intercellular spaces, necrosis and cellular damage. Melatonin supplementation to rats given Thyroxin (G3) improved the testicular mass and the cell damage. On the contrary, melatonin supplementation to rats given carbimazole (G5) did not show any improvement on both morphometrical and histological levels.

Conclusion: It was concluded that simultaneous melatonin administration effectively depresses the negative effects of hyperthyroidism but not hypothyroidism on the adult male rat testis.
\end{abstract}

Key Words: Albino rat, hyperthyroidism, hypothyroidism, melatonin, testis.

Received: 13 February 2016, Accepted: 30 April 2017

Corresponding Author: Hala Z. E. Mohamed, Tel.: 00201063126036, E-mail: hala.zeinabdin@yahoo.com

ISSN: 1110-0559, March 2017, Vol. 40, No. 1

\section{INTRODUCTION}

Among hormones secreted by the thyroid gland, thyroxine (T4) is the most abundant form. It is converted to the active hormone triiodothyronine (T3) bydeiodinase enzymes. Thyroid hormone level can severely affect the reproductive functions including fertility in humans and rats $^{[1]}$. Hyperthyroidism is associated with an increase in the concentration of thyroid hormones and an increase in the speed of the basal metabolism, accompanied by an increase in the $t$ otal consumption of oxygen. In untreated patients, hyperthyroidism increases the formation of reactive oxygen species (ROS) leading to an oxidative damage to the biomembrane lipids ${ }^{[2]}$. Dahmani-Said et al. ${ }^{[1]}$ found that rats received thyroxine were hyperthyroidic as compared to age-matched control and hyperthyroidism affected both; the seminiferous tubules and the testicular interstitium ${ }^{[1]}$. On the other hand, hypothyroidism can cause an impairment of the reproductive efficiency of the adult male $\operatorname{rats}^{[3]}$. The treatment of normothyroidic rats with antithyroid drugs was found to induce a maturation arrest of spermatogenesis, reduced the number of Leydig cells, decreased tubular diameter, an interstitial edema and thickening of the basement membrane ${ }^{[1]}$. Carbimazole is a derivative of methimazole which is wconverted into methimazole in the body and commonly used as antithyroid drug. It is used to induce hypothyroidism in the animal models ${ }^{[4,5]}$.

Melatonin (N1- acetyl- N2- formyl- 5methoxykynuramine) is synthesized mainly by the pineal gland and is suggested to have an antioxidant 
and prophylactic properties ${ }^{[6]}$. Studies have shown that melatonin is significantly better than the classic antioxidants in resisting free-radical-based molecular destruction $^{[2,6]}$. Melatonin was more effective than vitamin $\mathrm{E}, \beta$-carotene, vitamin $\mathrm{C}$ and superior to the garlic oil ${ }^{[2]}$. However, up to our knowledge, there is no previous research concerned with the effects of the simultaneous melatonin administration to experimentally induced hyperand hypothyroidism on the testis of adult male albino rats.

Thus, this study was performed in order to determine the histological and morphometrical effects of melatonin on the testis in models of hyperthyroidic and hypothyroidic adult male albino rats.

\section{MATERIALS AND METHODS}

\section{Experimental Animals}

This study was carried out on 50 adult male albino rats, weighing (200 -250) gm. The rats were housed in the animal house of Assiut niversity in cages containing bedding of fine wood which was changed twice weekly. They were maintained under light dark cycle (12/ 12) hours, at a $(25 \pm 5) \mathrm{C}^{\mathrm{o}}$. All rats were supplied with food and water ad-libitum. This experiment was complied with the known guidelines of animal ethics committee, which were established in accordance with the internationally accepted principles for laboratory animal use and care.

\section{Experimental Design}

Animals were randomly divided into five groups:

\section{Group 1:}

It was considered as control group. The animals of this group administrated distilled water.

\section{Group 2 (hyperthyroidic group):}

The animals of this group were treated with thyroxin, T2376 (Sigma -Aldrich, St Louis Co., MO, USA) (0.2 mg/ $\mathrm{kg} \mathrm{b.w})$ orally ${ }^{[1,7]}$ by the way of gastric tube for 15 days.

\section{Group 3 (hyperthyroidic+melatonin group):}

The animals of this group were treated with thyroxin $(0.2 \mathrm{mg} / \mathrm{kg} \mathrm{b.w})^{[1,7]}$ and melatonin, M5250 (Sigma -Aldrich, St Louis Co., MO, USA) $(2.5 \mathrm{mg} / \mathrm{kg} \mathrm{b.w})$ orally $^{[6]}$ by the way of gastric tube for 15 days.

\section{Group 4 (hypothyroidic group):}

The animals of this group were treated with carbimazole, SML0931 (Sigma -Aldrich, St Louis Co., MO, USA) (1.35mg/kg b.w) dissolved in water; equivalent to the therapeutic dose for human orally ${ }^{[12]}$ by the way of gastric tube for 15 days.

\section{Group 5 (hypothyroidic+melatonin group):}

The animals of this group were treated with carbimazole $(1.35 \mathrm{mg} / \mathrm{kg}$ b.w /day) and melatonin $(2.5 \mathrm{mg} / \mathrm{kg} \mathrm{b.w})$ orally ${ }^{[6,12]}$ by the way of gastric tube for 15 days.

\section{Histological study}

At the end of experiment, the animals were first anaesthetized by chloroform. Each animal was fixed in a dissecting dish through its four limbs. The chest was opened to expose the heart for intracardiac perfusion with $10 \mathrm{ml}$ of heparinised isotonic saline solution to facilitate testicular perfusion followed by perfusion with $2 \%$ gluteraldehyde in phosphate buffer. The wall of the scrotum was dissected and the testis was extracted and the testicular mass was detected. The specimens (1x1 mm thickness) were fixed in glutaraldehyde for $20 \mathrm{~h}$, and then fixed in $1 \%$ osmium tetroxide. Semithin sections $(1 \mu \mathrm{m})$ were prepared and stained with $1 \%$ toluidine blue in borax and examined under a light microscope. Ultrathin sections of 50nm were cut by an ultramicrotome, mounted on copper grids and stained with uranyle acetate and lead citrate and carried on copper grids ${ }^{[8]}$. The grids were examined and photographed with transmission electron microscope (Jeol- JEM- 100 CXII; Jeol, Tokyo, Japan) in the Assiut University Electron Microscopic Unit.

\section{Statistical analysis}

The scrotal wall was dissected and the right testis was extracted after the removal of the epididymis. The mass of the testis was estimated. The data were analyzed using Graph-Pad Software program, San Diego, California, USA (Version 4). The results were expressed as means \pm SD (standard deviation). Histogram was constructed and statistical analysis was done through a student's (t) test to compare the means between the different groups. The $\mathrm{P}$ value was calculated and level of significance was considered as follows: (i) $p>0.05$, non-significant; (ii) $p \leq 0.05$, significant.

\section{RESULTS}

\section{I- Histological Results:}

\section{Control group (group 1):}

Light microscopic examination of the semithin sections of the testis of control albino rat showed that; the testicular tissue was formed of a group of seminiferous tubules with patent lumina containing spermatozoa, regular intact basement membranes and interstitial tissue among the tubules (Fig. 1). Each tubule was lined by germinal epithelium formed of spermatogenic cells 
at different stages of development (spermatogonia, spermatocytes, spermatids and spermatozoa) that were arranged from the base to the lumen of the tubules and Sertoli cells in between (Fig. 2).

Two types of spermatogonia were recognized; type A and type B. Type A spermatogonia were characterized by their large size, extensive contact with the basement membrane and oval nuclei. Type B spermatogonia appeared smaller with less contact area with the basement membrane than type A. The nucleus was spherical with multiple chromatin masses attached to the inner aspect of the nuclear membrane. Pachytene stage primary spermatocytes appeared as large cells with spherical nuclei containing deeply stained short and thick chromatin filaments. Cap phase spermatids were small rounded cells with spherical nuclei and covered by acrosomal cap. Sertoli cells appeared as tall cells extending from the basement membrane of the seminiferous tubule to its lumen and situated between the cells of germinal epithelium. It was difficult to determine the outline of the cells as they were obscured by the surrounding germ cells. The nuclei appeared elongated pale with prominent deeply stained nucleoli and surrounded by pale cytoplasm. In between the tubules, the interstitial tissue contained blood vessels and interstitial cells (Leydig cells) that were arranged into small clumps, had spherical or polyhedral shape with rounded or oval vesicular nuclei and pale vacuolated cytoplasm (Fig. 2).

By electron microscopic examination, the basement membrane appeared regular and intact. It revealed myoid cells (Figs. 3- 4). Sertoli cells nuclei were large, located in the basal region and appeared more or less oval with indented nuclear membrane. The nuclei contained fine granular homogenous chromatin and prominent centrally located large nucleoli. Sertoli cells cytoplasm contained abundant organelles in the form of ribosome, mitochondria and abundant smooth and rough endoplasmic reticulum cisternae (Fig. 3). As regarding type A spermatogonia, the nuclei were large, elongated ovoid and contained fine euchromatin and prominent large nucleoli. The cytoplasm contained free ribosomes and mitochondria. Type B spermatogonia had more or less rounded nuclei with clumps of marginated heterochromatin (Fig. 4). The pachytene primary spermatocytes had rounded nuclei with evenly distributed granular chromatin material. The cytoplasmic organelles were numerous. Smooth endoplasmic reticulum was present in great amounts. In addition there were numerous free ribosomes (Fig. 5). The cap phase spermatid was seen with spherical nucleus. The acrosomal cap spread over one pole of the nucleus. The cytoplasm contained smooth endoplasmic reticulum and mitochondria (Fig. 6). As regarding Leydig cells, the nuclei were oval with thin peripheral rim of chromatin material and fine indentation. The cytoplasm contained abundant lipid droplets (Fig. 3).

\section{Hyperthyroidic group (group 2):}

The light microscopic examination of the hyperthyroidic group (group 2) revealed deformed seminiferous tubule and irregular basement membrane. Many tubules showed obliteration of their lumina by residual spermatic bodies (Fig. 7). Some tubules were surrounded by relatively thick myoid cells and lined by disorganized germ cells with empty spaces in between the cells (Fig. 8). Additionally, interstitial tissue revealed interstitial oedema and thick walled dilated blood vessels were seen (Figs. 7, 8). The type A spermatogonia had vacuolated cytoplasm. Type B spermatogonia appeared losing contact with the basement membrane. Cap phase spermatids appeared shrunken. Pachytene primary spermatocytes were more or less normal. Sertoli cell nucleus had no nucleolus and separated from the basement membrane. Leydig cells appeared oval, shrunken and darkly stained (Fig. 9).

The electron microscopic examination of the basement membrane revealed irregular outline of the myoid cells nuclei. The nucleus of type A spermatogonia lost its oval shape. Type B spermatogonia had an electron dense cytoplasm (Fig. 10). Pachytene primary spermatocytes and cap phase spermatids had irregular nuclei and degenerated cytoplasm that showed destructed and swollen mitochondria and apparent decrease in the amount of ribosomes (Fig. 11). Abnormally located sperms were observed (Fig. 11). The Sertoli cells nuclei were irregular. The cytoplasm contained vacuoles, swollen mitochondria and large lipid droplets (Fig. 10). The Leydig cells showed condensed peripheral chromatin material of the nuclei and destructed and displaced cell membrane. Electron dense and swollen mitochondria could be observed (Fig. 12).

\section{Hyperthyroidic + melatonin group (group 3):}

Light microscopic examination of the semithin sections of the testis of Hyperthyroidic+melatonin group (group 3) albino rats showed that the seminiferous tubules were more or less like control group with patent lumina containing spermatozoa and interstitial tissue among the tubules (Fig. 13). Type A spermatogonia, type B spermatogonia, pachytene primary spermatocytes, cap phase spermatids and Sertoli cells were more or less like control group (Fig. 14). In between the tubules, the interstitial tissue contained blood vessels and interstitial cells (Leydig cells) that were arranged into small clumps and had spherical or polyhedral shape with rounded or oval vesicular nuclei and pale vacuolated cytoplasm (Fig. 14).

By electron microscopic examination, the basement membrane appeared regular and intact (Figs. 15, 17). The myoid cells surrounding the basement membrane were seen (Fig. 18). Type A spermatogonia were more or less normal 
and type B spermatogonia had more or less rounded nuclei with clumps of marginated heterochromatin (Figs. 15, 17). The primary spermatocytes were more or less normal. Cap phase spermatids were more or less intact with cytoplasm containing abundant smooth endoplasmic reticulum, mitochondria and ribosomes (Figs. 15, 17). Sertoli cells nuclei were oval with indented outline. The cytoplasm contained mitochondria that appeared more or less healthy and numerous free ribosomes (Fig. 16). The Leydig cells nuclei were round or oval with thin peripheral rim of chromatin and fine indentation. The cytoplasm contained lipid droplets and mitochondria (Fig. 18).

\section{Hyperthyroidic + melatonin group (group 3):}

Light microscopic examination of the semithin sections of the testis of Hyperthyroidic + melatonin group (group 3) albino rats showed that the seminiferous tubules were more or less like control group with patent lumina containing spermatozoa and interstitial tissue among the tubules (Fig. 13). Type A spermatogonia, type B spermatogonia, pachytene primary spermatocytes, cap phase spermatids and Sertoli cells were more or less like control group (Fig. 14). In between the tubules, the interstitial tissue contained blood vessels and interstitial cells (Leydig cells) that were arranged into small clumps and had spherical or polyhedral shape with rounded or oval vesicular nuclei and pale vacuolated cytoplasm (Fig. 14).

By electron microscopic examination, the basement membrane appeared regular and intact (Figs. 15, 17). The myoid cells surrounding the basement membrane were seen (Fig. 18). Type A spermatogonia were more or less normal and type B spermatogonia had more or less rounded nuclei with clumps of marginated heterochromatin (Figs. 15, 17). The primary spermatocytes were more or less normal. Cap phase spermatids were more or less intact with cytoplasm containing abundant smooth endoplasmic reticulum, mitochondria and ribosomes (Figs. 15, 17). Sertoli cells nuclei were oval with indented outline. The cytoplasm contained mitochondria that appeared more or less healthy and numerous free ribosomes (Fig. 16). The Leydig cells nuclei were round or oval with thin peripheral rim of chromatin and fine indentation. The cytoplasm contained lipid droplets and mitochondria (Fig.18).

\section{Hypothyroidic group (group 4):}

The light microscopic examination of the semithin sections of the testis of the hypothyroidic group (group 4) revealed seminiferous tubules with lumen devoid of spermatozoa and obliterated seminiferous tubules lumina with debris (Figs. 19, 21). Additionally, some tubules were lined by disorganized germ cells with empty spaces in between the cells (Fig. 21). Degenerated type A spermatogonia, type B spermatogonia, pachytene primary spermatocytes, cap phase spermatids and displaced
Sertoli cells were observed. An oedematous interstitial tissue among the tubules revealing dilated blood vessel and shrunken darkly stained Leydig cells were observed (Figs. 19-21).

By electron microscopic examination, type A spermatogonia had vacuolated cytoplasm (Fig. 24). The nuclei of type B spermatogonia were surrounded by empty space and the pachytene primary spermatocyte nuclei had heterochromatin. The cytoplasm was scanty and contained vacuoles, lysosomes and destructed mitochondria in some views (Figs. 22- 24). Electron dense cytoplasm was detected in others (Fig. 25). Cap phase spermatids revealed scanty and degenerated cytoplasm (Fig. 25). Sertoli cell cytoplasm was also scanty containing lysosomes, destructed mitochondria and vacuoles (Fig. 22). Leydig cells with ill defined cellular membrane, irregular nuclear membrane and marginal clumps of heterochromatin were observed (Fig. 26).

\section{Hypothyroidic + melatonin group (group 5):}

The light microscopic picture of a semithin section in the seminiferous tubules of the testis of albino rat of hypothyroidic+melatonin group (group 5) revealed seminiferous tubules surrounded by a destructed basement membrane, were empty of spermatozoa and contained vacuoles. Type A spermatogonia, type B spermatogonia, pachytene primary spermatocytes, cap phase spermatids and Sertoli cells were degenerated. Abnormally located spermatozoa were located near the basement membrane. Degenerated interstitial tissue among the tubules contained dilated thick walled blood vessel. Shrunken darkly stained Leydig cells were noticed (Figs. 27- 28).

By electron microscopic examination, the basement membrane was deformed (Fig. 30). Type A spermatogonia cytoplasm contained lipid droplets (Fig. 33). Type B spermatogonia cytoplasm contained degenerated mitochondria (Fig. 30). The nucleus was surrounded by an empty space (Fig. 29). The pachytene primary spermatocyte had shrunken nucleus in some views (Fig. 30). In others, the nucleus contained heterochromatin with indentation and discontinuation of the nuclear membrane. A destructed cell membrane and lysosomes in the cytoplasm were observed (Fig. 31). Nucleus of cap phase spermatid with light acrosome was observed (Fig. 30). Abnormally located spermatozoa among the degenerated cells revealing vacuoles, destructed mitochondria and lysosomes were observed (Fig. 32). The Sertoli cell nuclei were devoid of nucleoli in some views (Fig. 29) and broken in others (Fig. 30). The cytoplasm was scanty, contained vacuoles (Fig. 29) and was degenerated (Fig. 30). The interstitial tissue was degenerated (Fig. 29). Leydig cells with peripheral heterochromatin and ill-defined cytoplasmic organelles were noticed (Fig. 33) 


\section{II-Morphometrical Results:}

The present work revealed that, the means \pm SD of the testicular mass of the group 1, group 2 and group 3 were $(12.30 \pm 2.41) \mathrm{gm},(8.40 \pm 1.98)$ gm and $(12.25 \pm 2.37)$, respectively. The student t-test showed that, the differences between groups ( 1 and 2 ) and ( 2 and 3 ) were significant (Table 1 and histogram 1 ). The means \pm SD of the testicular mass of the group 1, group 4 and group 5were $(12.30 \pm 2.41) \mathrm{gm},(8.19 \pm 1.83)$ and $(8.86 \pm 2.17) \mathrm{gm}$, respectively. The student t-test showed that, the differences between groups (1 and 4) and (1 and 5) were significant (Table 2 and Histogram 2).

Table 1: The Mean \pm SD of the Testicular Mass of Groups 1, 2 and 3

\begin{tabular}{|c|c|c|c|c|c|c|}
\hline & Group 1 & Group 2 & Group 3 & & P-value & \\
\hline & & & & 1 vs. 2 & 1 vs. 3 & 2 vs. 3 \\
\hline Mean \pm SD & $12.30 \pm 2.41$ & $8.40 \pm 1.98$ & $12.25 \pm 2.37$ & $0.006^{*}$ & 0.978 & $0.005^{*}$ \\
\hline
\end{tabular}

Table 2: The Mean \pm SD of the Testicular Mass of Groups 1, 4 and 5

\begin{tabular}{|c|c|c|c|c|c|c|}
\hline & Group 1 & Group 4 & Group 5 & & P-value & \\
\hline & & & & 1 vs. 4 & 1 vs. 5 & 4 vs. 5 \\
\hline Mean \pm SD & $12.30 \pm 2.41$ & $8.19 \pm 1.83$ & $8.86 \pm 2.17$ & $0.004 *$ & $0.013^{*}$ & 0.499 \\
\hline
\end{tabular}

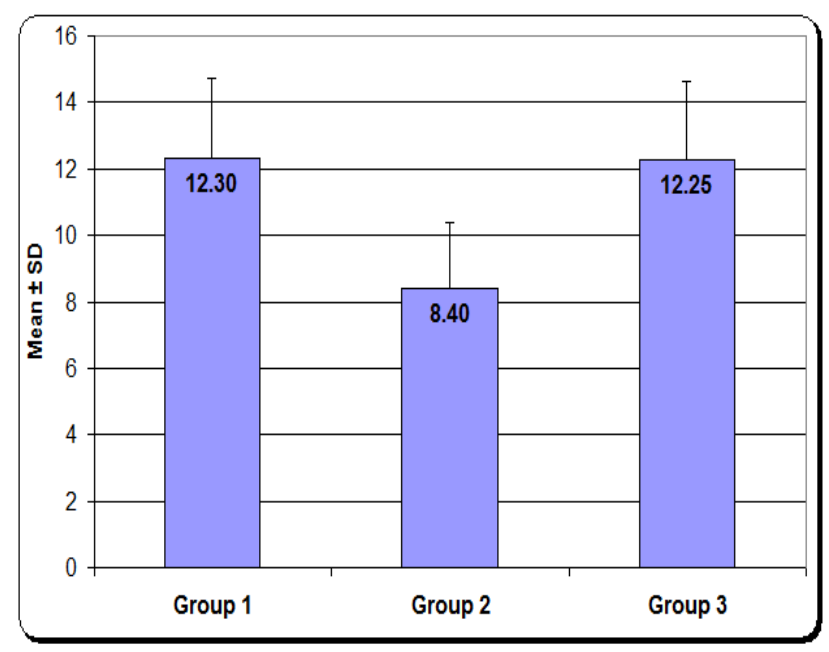

Histogram 1: The mean $\pm \mathrm{SD}$ of the testicular mass for groups 1, 2 and 3.

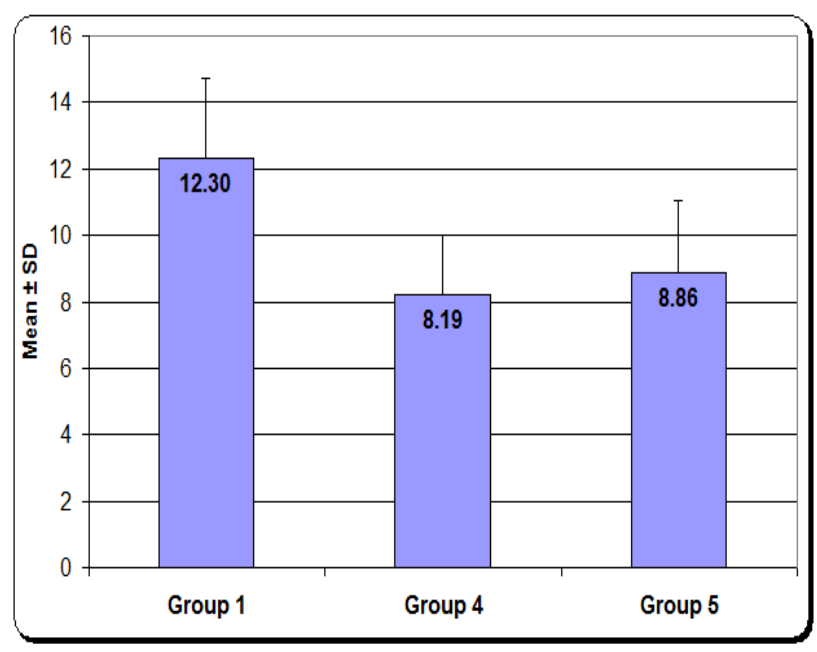

Histogram 2: The mean $\pm \mathrm{SD}$ of the testicular mass for groups 1,4 and 5 . 


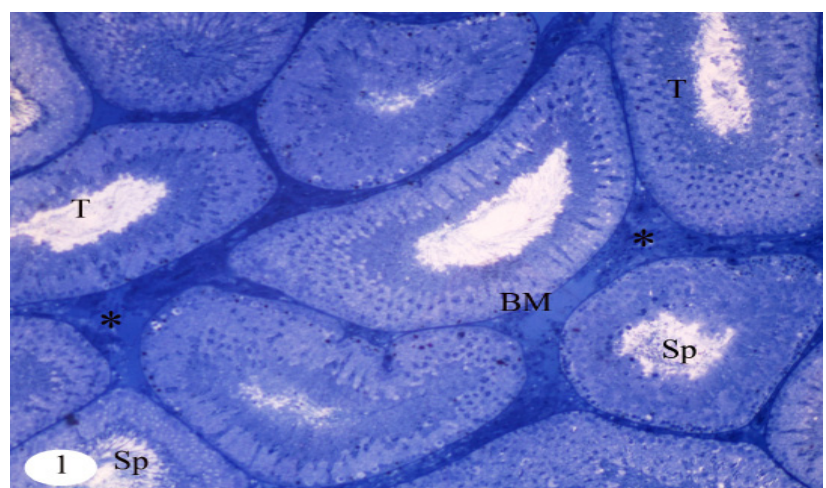

Fig. 1: A photomicrograph of a semithin section in the testis of control albino rat (group 1) showing; a group of seminiferous tubules $(\mathrm{T})$ with patent lumen containing spermatozoa $(\mathrm{Sp})$, regular intact basement membranes (BM) and interstitial tissue $(*)$ among the tubules.

Toluidine blue, X100

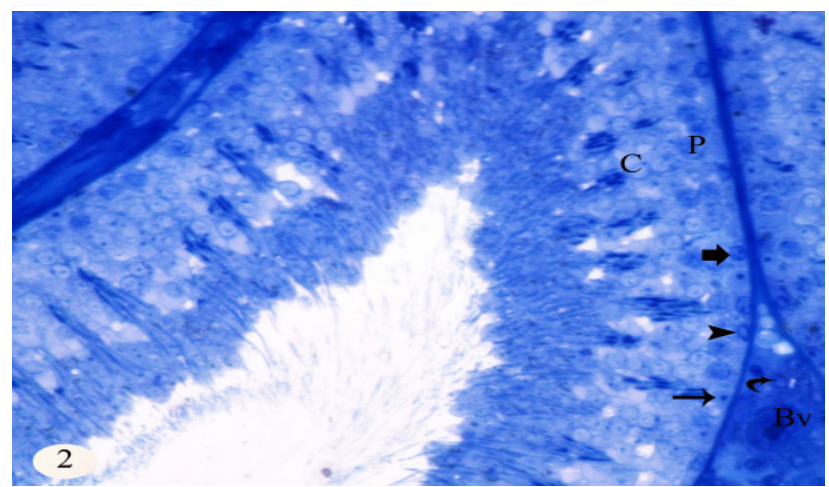

Fig. 2: A photomicrograph of a semithin section in the testis of control albino rat (group1) showing; spermatogonia type A (arrow head), spermatogonia type B (thick arrow), pachytene primary spermatocyte $(\mathrm{P})$, cap phase spermatid $(\mathrm{C})$ and the nuclei of Sertoli cell (thin arrow) that appear elongated pale with prominent deeply stained nucleoli. The interstitium contains blood vessels (Bv) and Leydig cells (curved arrow) that are arranged into small clumps and have spherical or polyhedral shape with rounded or oval vesicular nuclei and pale vacuolated cytoplasm.

Toluidine blue, X400

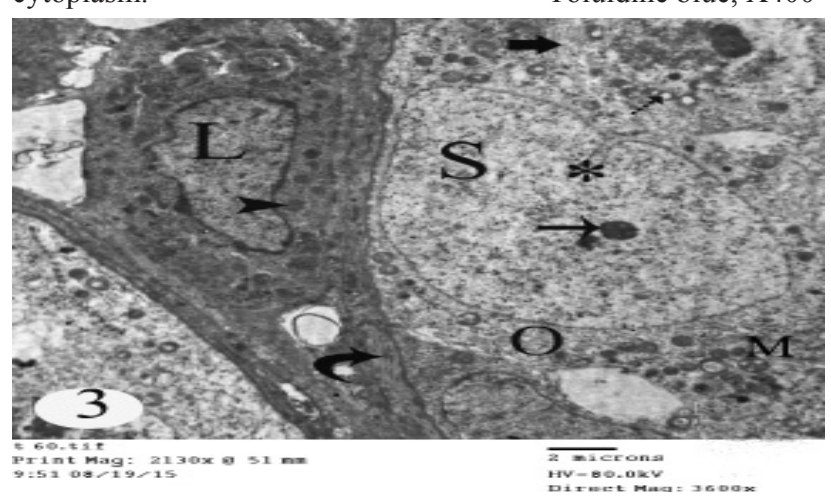

Fig. 3: An electron micrograph of control albino rat testis (group 1) showing; regular intact basement membrane revealing myoid cell nucleus (curved arrow), Sertoli cell nucleus (S) that is more or less oval and located in the basal region with fine granular homogenous chromatin, prominent nucleolus (thin arrow) and indented outline $(*)$. The cytoplasm contains ribosomes $(\mathrm{O})$, rough endoplasmic reticulum (thick arrow), mitochondria (M) and smooth endoplasmic reticulum (broken arrow). The Leydig cell nucleus (L) is oval with thin peripheral rim of chromatin and fine indentation. The cytoplasm contains lipid droplets (arrow head)

X3600

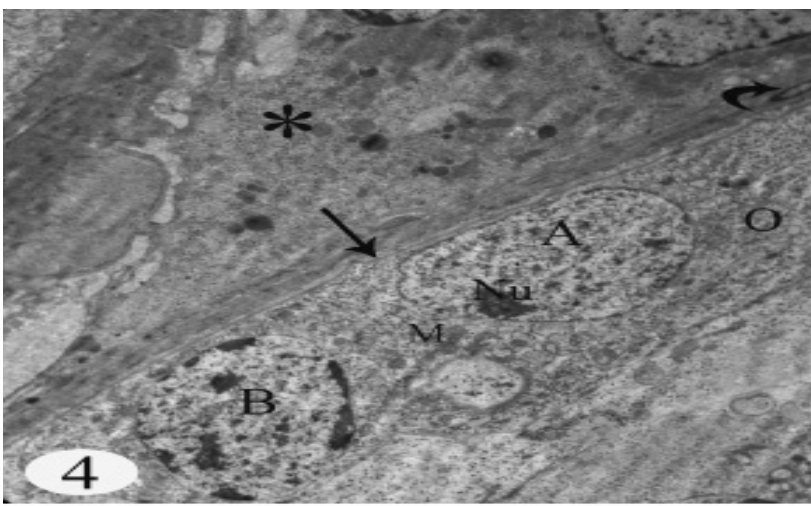

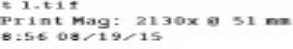

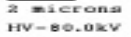

Fig. 4: An electron micrograph of control albino rat testis (group 1) showing; regular intact basement membrane (thin arrow) revealing myoid cell (curved arrow), type A spermatogonia with a large elongated ovoid nucleus (A) containing fine euchromatin and a prominent nucleolus $(\mathrm{Nu})$ and the cytoplasm contains free ribosomes $(\mathrm{O})$ and mitochondria $(\mathrm{M})$ and type $\mathrm{B}$ spermatogonia having more or less rounded nucleus (B) with clumps of marginated heterochromatin. Notice the adjacent interstitium $(*)$.

$\mathrm{X} 3600$

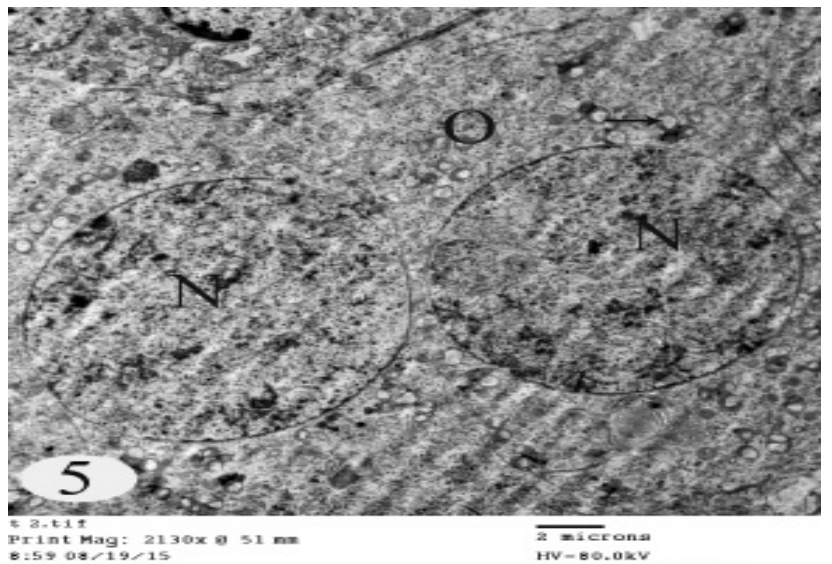

Fig. 5: An electron micrograph of primary spermatocytes (pachytene stage) of control albino rat testis (group 1) showing; the cells have rounded nuclei $(\mathrm{N})$ with evenly distributed granular chromatin material. Notice the presence of smooth endoplasmic reticulum (arrow) and free ribosomes (O) in the cytoplasm. X3600

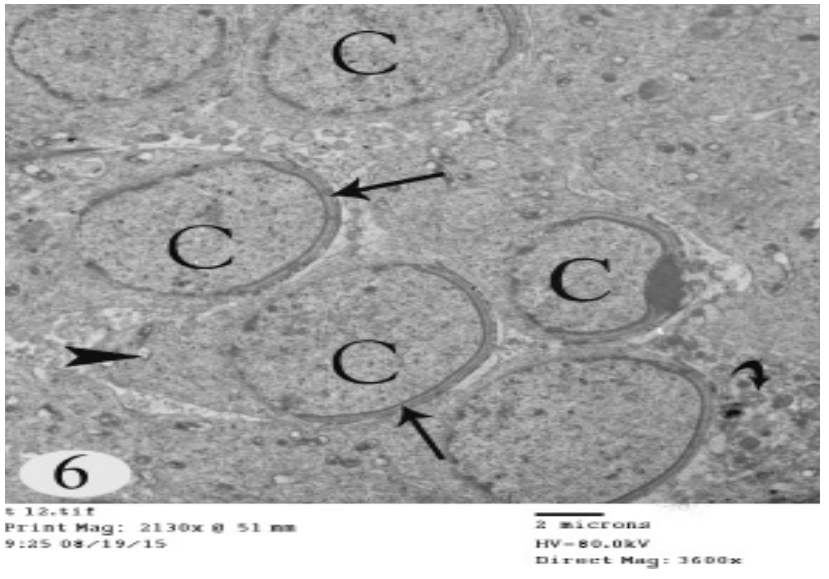

Fig. 6: An electron micrograph of control albino rat testis (group 1) showing cap phase spermatids with spherical nuclei (C) The acrosomal cap spreads over only one pole of the nucleus (thin arrows). The cytoplasm contains smooth endoplasmic reticulum (arrow head) and mitochondria (curved arrow).

X3600 


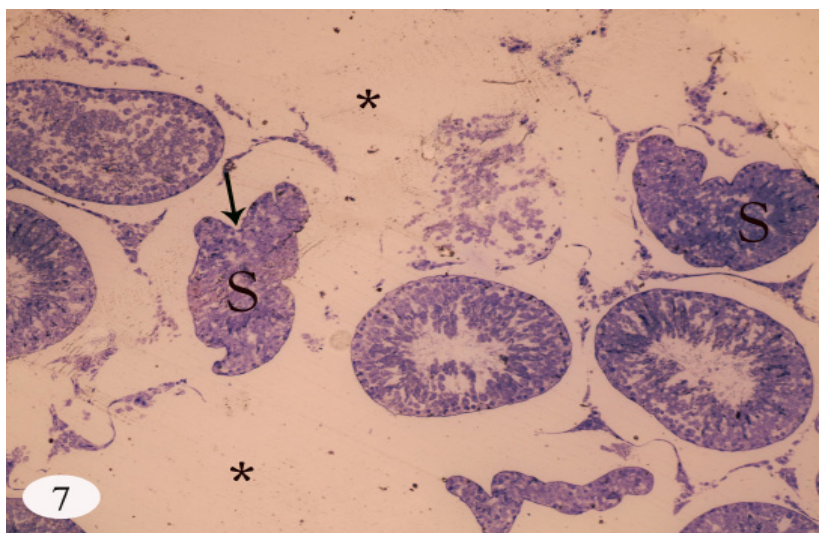

Fig. 7: A photomicrograph of a semithin section in the testis of albino rat (group 2) showing deformed seminiferous tubules with irregular basement membrane (arrow). The tubular lumen is obliterated by residual spermatic bodies (S). Notice, the interstitial tissue $(*)$ reveals oedema. Toluidine blue, X100

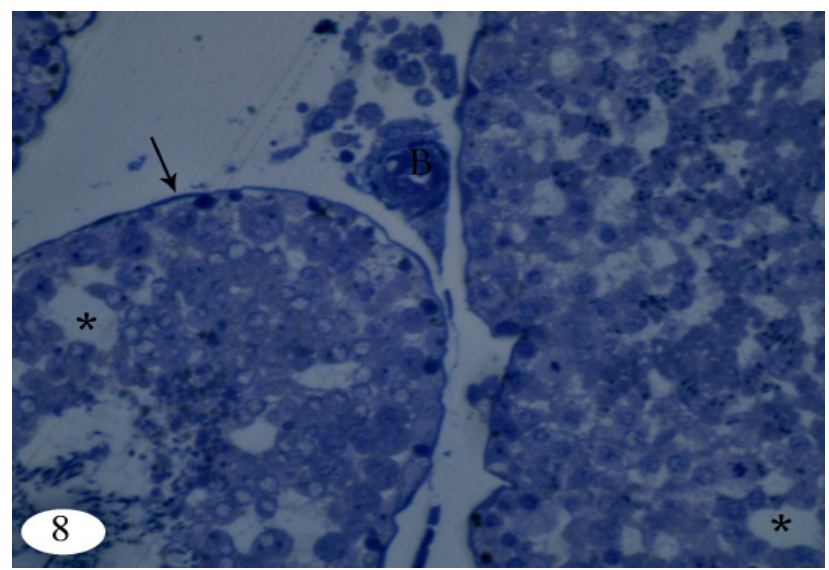

Fig. 8: A photomicrograph of a semithin section in the testis of albino rat (group 2) showing; seminiferous tubules lined by disorganized germ cells with empty spaces $\left(^{*}\right)$ in between the cells, relatively thick myoid cells (arrow) and thick walled dilated blood vessels (B) in the interstitial tissue. Toluidine blue, X400

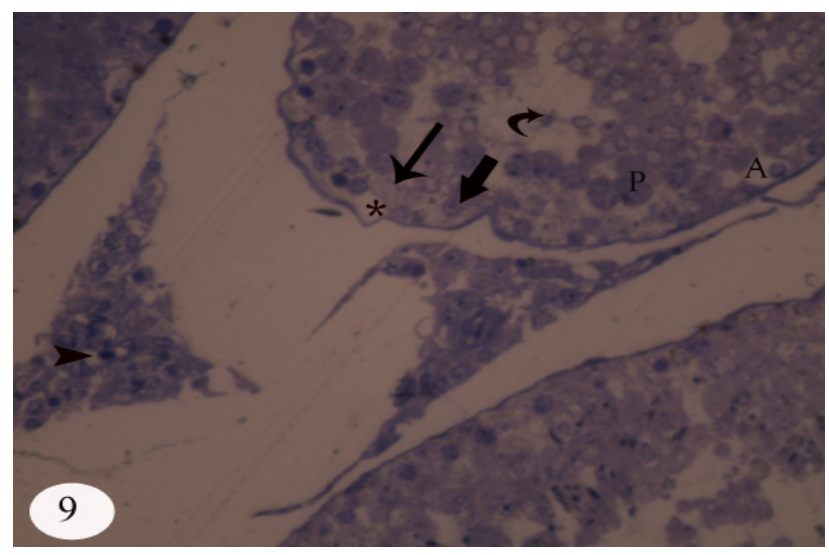

Fig. 9: A photomicrograph of a semithin section in the testis of albino rat (group 2) showing; type A spermatogonia (A) with vacuolated cytoplasm, type B spermatogonia (thick arrow) is losing contact with the basement membrane and cap phase spermatid (curved arrow) that appears shrunken. Pachytene primary spermatocyte $(\mathrm{P})$ is more or less normal. Sertoli cells (thin arrow) appear with no nucleoli and separated from the basement membrane. Notice, the Leydig cell (arrowhead) appears shrunken, oval and darkly stained.

Toluidine blue, X400

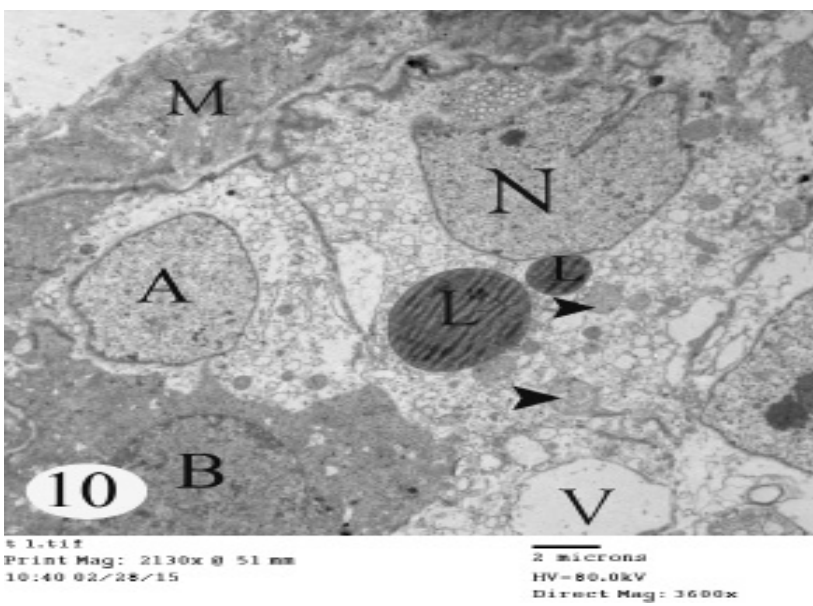

Fig. 10: An electron micrograph of albino rat testis (group 2) showing irregular outline of myoid cell nucleus (M). The nucleus of type A spermatogonia (A) loses its oval shape. Electron dense cytoplasm of type B spermatogonia (B) is observed. Notice an irregular Sertoli cell nucleus (N), vacuolated cytoplasm (V), wollen mitochondria (arrowheads) and large lipid droplets (L).

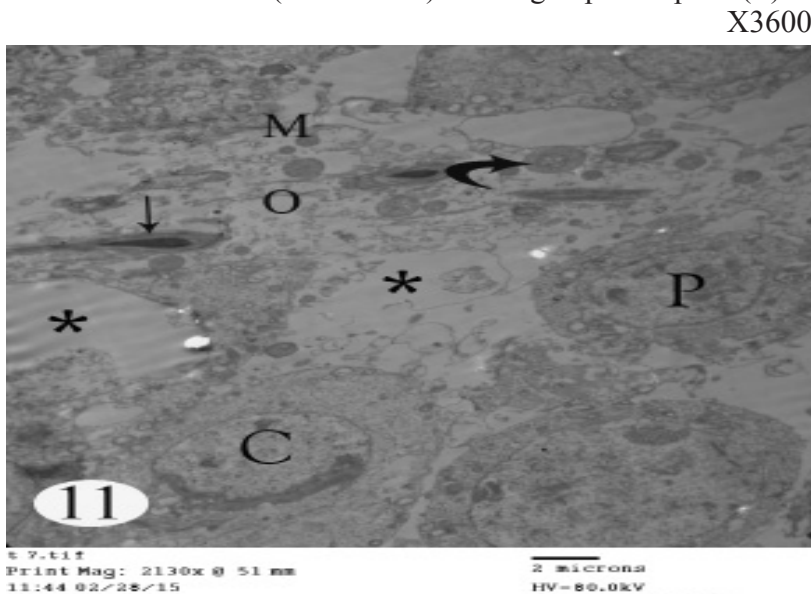

Fig. 11: An electron micrograph of albino rat testis (group 2) showing; pachytene primary spermatocyte $(\mathrm{P})$ and irregula nucleus of cap phase spermatid (C). Degenerated cytoplasm (*) shows destructed (M) and swollen (curved arrow) mitochondria. Notice the apparent decrease in the amount of ribosomes $(\mathrm{O})$ and abnormally located sperms (arrow).

X3600

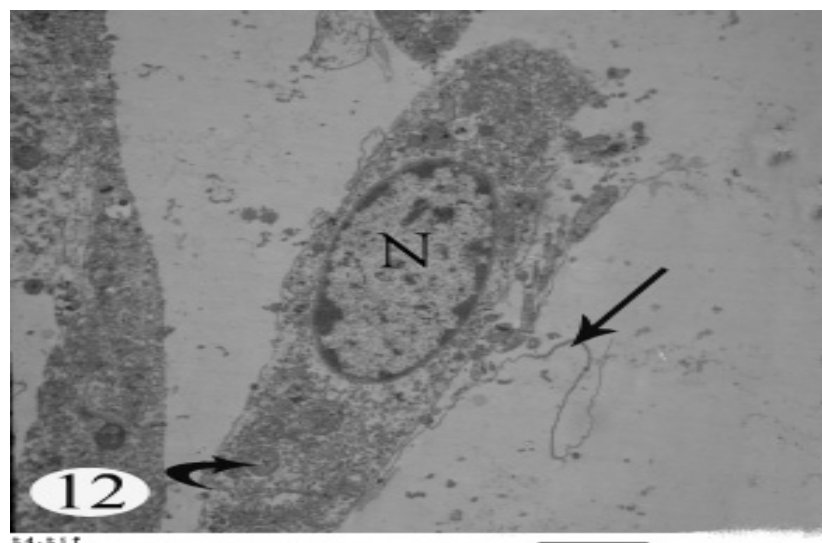

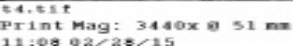

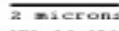

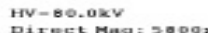

Fig. 12: An electron micrograph of Leydig cell of albino rat testis (group 2) showing; condensed peripheral chromatin material of the nucleus $(\mathrm{N})$, the destructed and displaced cell membrane (arrow) and electron dense and swollen mitochondria (curved arrow).

X5800 


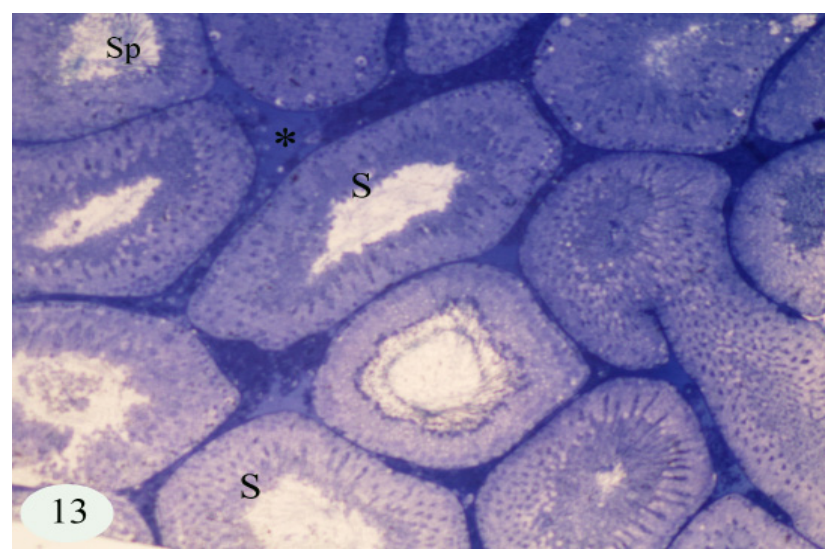

Fig. 13: A photomicrograph of a semithin section in the testis of albino rat (group 3) showing; seminiferous tubules (S) that appear more or less like control group with patent lumen containing spermatozoa ( $\mathrm{Sp})$ and interstitial tissue $\left({ }^{*}\right)$ among the tubules. Toluidine blue, X100

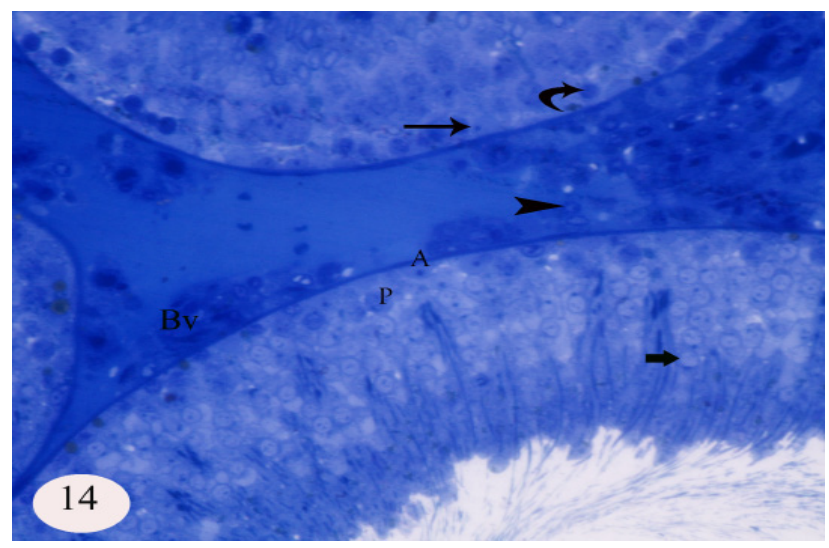

Fig. 14: A photomicrograph of a semithin section in the testis of albino rat (group 3) showing; type A spermatogonia (A), type B spermatogonia (curved arrow), pachytene primary spermatocyte (P), cap phase spermatid (thick arrow) and Sertoli cell (thin arrow) that are more or less normal. Leydig cells (arrowhead) are arranged into small clumps and have spherical or polyhedral shape with rounded or oval vesicular nuclei and pale vacuolated cytoplasm. Notice, the blood vessel (Bv) in the interstitium.

Toluidine blue, X400

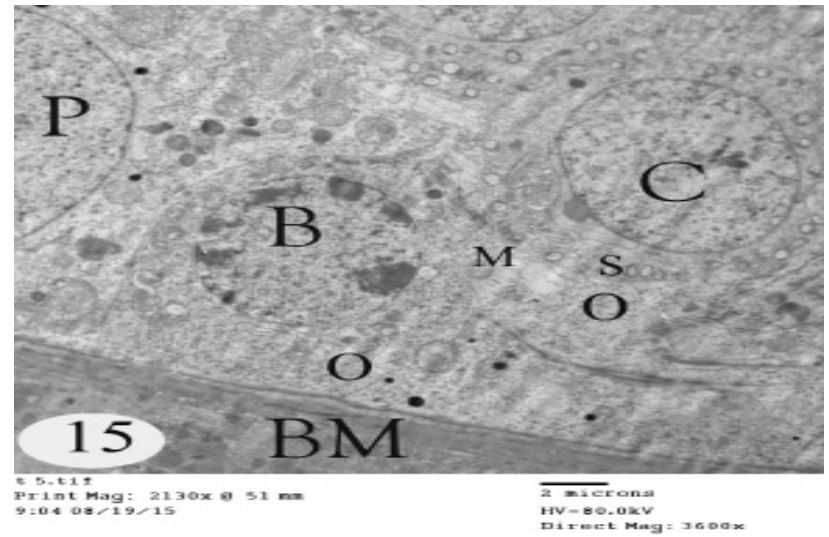

Fig. 15: An electron micrograph of albino rat testis (group 3) showing; regular and intact basement membrane (BM), type B spermatogonia have more or less rounded nucleus with clumps of marginated heterochromatin (B) and more or less intact cap phase spermatid (C). The cytoplasm of the cells has abundant smooth endoplasmic reticulum $(\mathrm{S})$, mitochondria $(\mathrm{M})$ and numerous free ribosomes $(\mathrm{O})$. Primary spermatocytes $(\mathrm{P})$ appear more or less normal in comparison to the control.

$\mathrm{X} 3600$

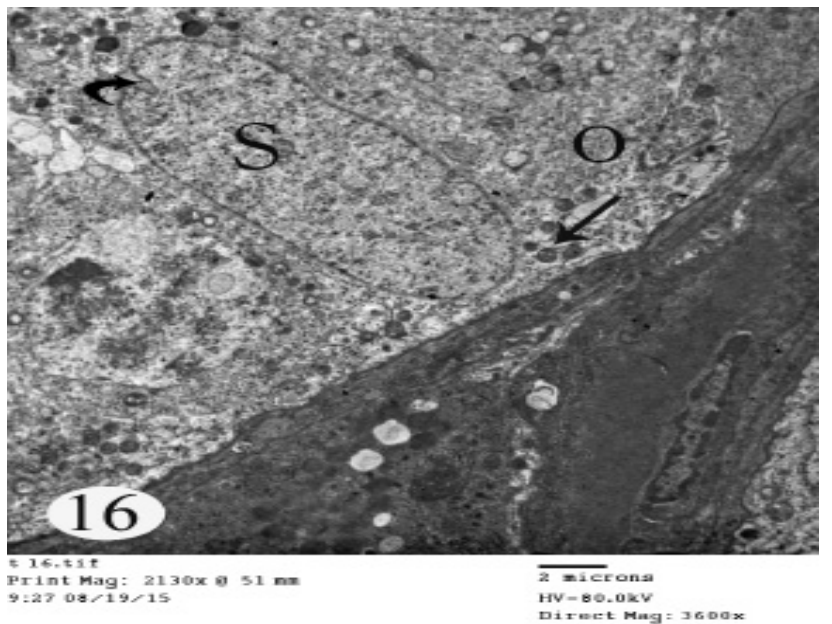

Fig. 16: An electron micrograph of albino rat testis (group 3) showing that the Sertolicell nucleus (S) is oval with indented outline (curved arrow). The cytoplasm containsmitochondria that appear more or less healthy (thin arrow) and numerous free ribosomes $(\mathrm{O})$.

$\mathrm{X} 3600$

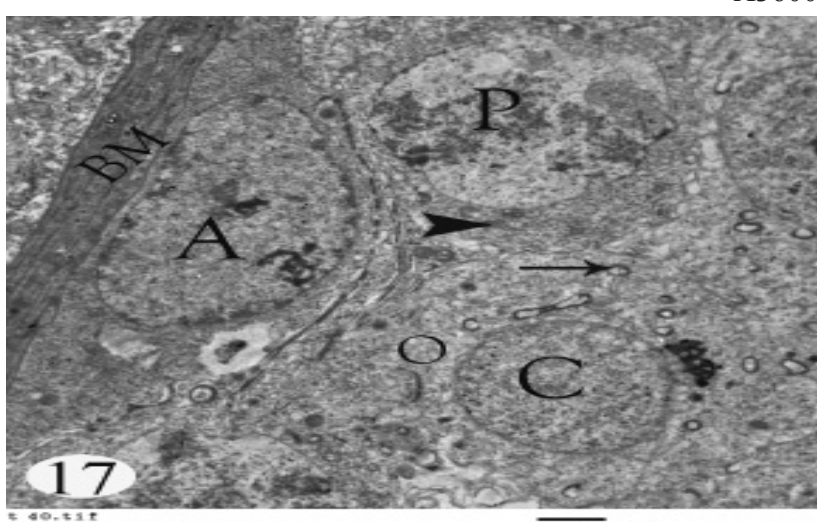

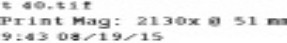
inicrona
Hy-80.0kV

Fig. 17: An electron micrograph of albino rat testis (group 3 ) showing; regular and intact basement membrane (BM), type A spermatogonia $(\mathrm{A})$ and pachytene primary spermatocyte $(\mathrm{P})$ that are more or less normal. Cap phase spermatid (C) cytoplasm contains ribosomes $(\mathrm{O})$ and smooth endoplasmic reticulum (arrow). An arrowhead points to mitochondria in the cytoplasm of the pachytene primary spermatocyte $(\mathrm{P})$.

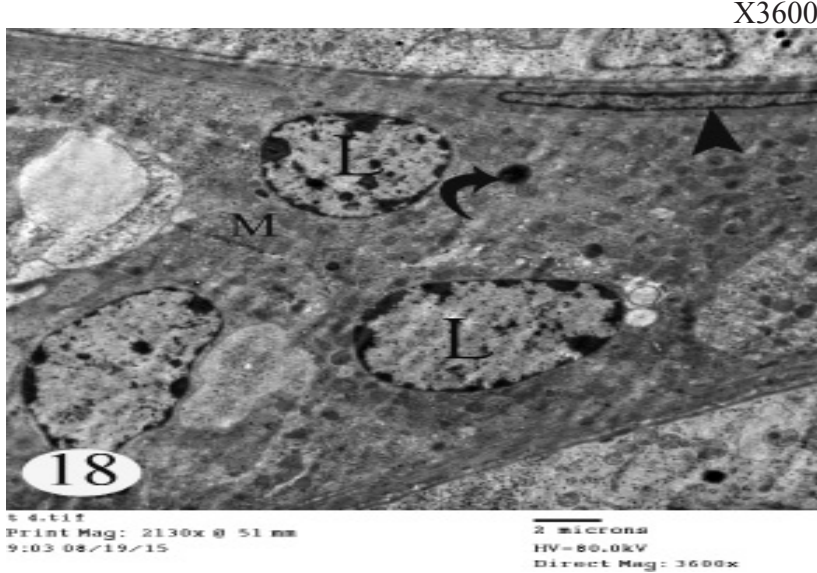

Fig. 18: An electron micrograph of albino rat testis (group 3) showing; the Leydig cell nucleus (L) is round or oval with thin peripheral rim of chromatin and fine indentation. The cytoplasm contains lipid droplets (curved arrow) and mitochondria (M). Notice the myoid cell surrounding the basement membrane arrowhead).

$\mathrm{X} 3600$ 


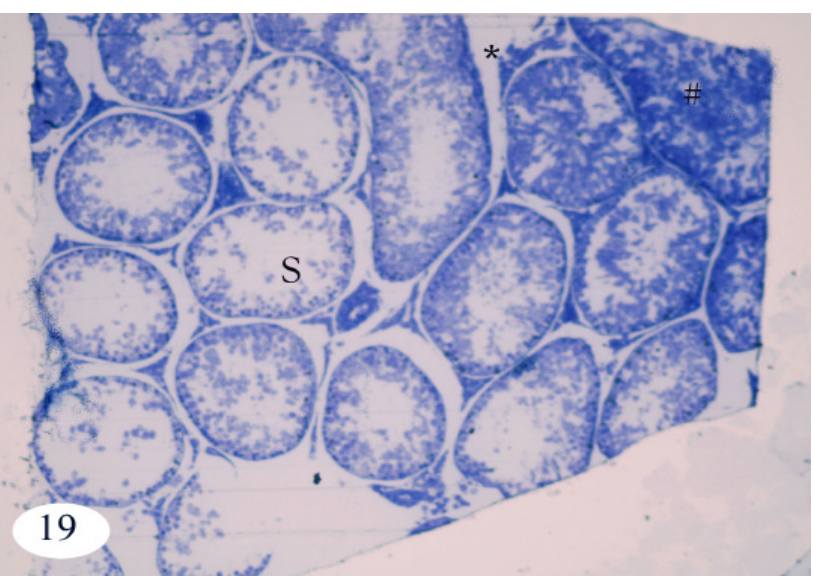

Fig. 19: A photomicrograph of a semithin section in the testis of albino rat (group 4) showing degenerated seminiferous tubules (S) with lumen devoid of spermatozoa. Some seminiferous tubules have obliterated lumen $(\#)$. Notice the oedematous interstitial tissue $(*)$.

Toluidine blue, X100

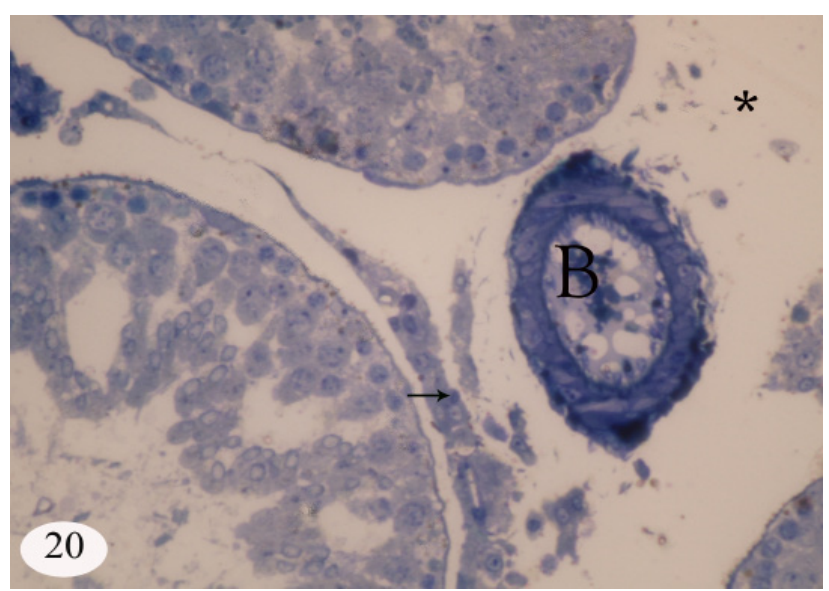

Fig. 20: A photomicrograph of a semithin section in the testis of albino rat (group 4) showing; interstitial tissue oedema $(*)$ among the tubules revealing dilated blood vessel (B) and shrunken darkly stained Leydig cell (arrow).

Toluidine blue, X400

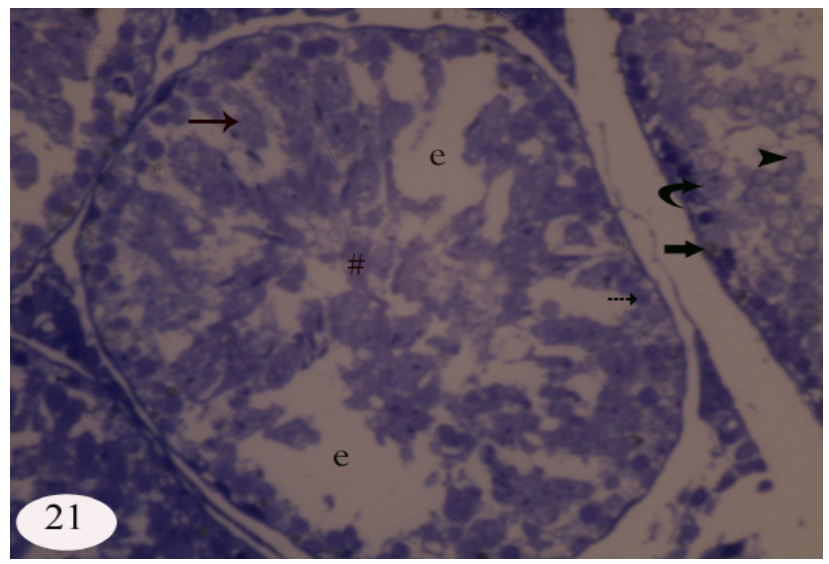

Fig. 21: A photomicrograph of a semithin section in the testis of albino rat (group 4) showing; seminiferous tubule with disorganized germ cells and obliterated lumen with debris (\#), empty spaces (e). Notice the degenerated type A spermatogonia (thick arrow), type B spermatogonia (broken arrow), pachytene primary spermatocytes (arrow) and cap phase spermatids (arrowhead). Sertoli cell nucleus (curved arrow) is displaced.

Toluidine blue, X400

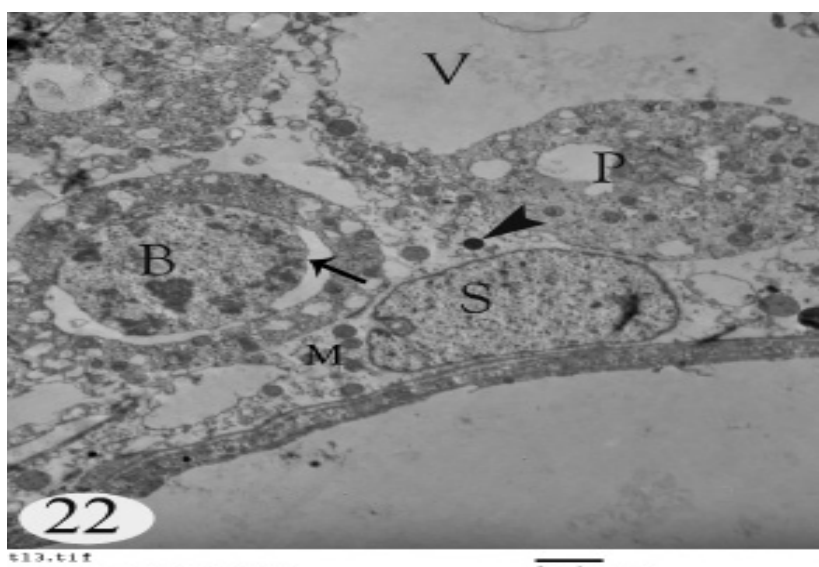

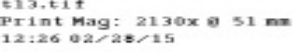

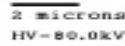

Fig. 22: An electron micrograph of albino rat testis (group 4) showing the degenerated pachytene primary spermatocyte $(\mathrm{P})$. The cytoplasm of Sertoli cell (S) is scanty and contains lysosomes (arrowhead), destructed mitochondria (M) and vacuoles (V). The nucleus of type B spermatogonia (B) is surrounded by an empty space (arrow).

$\mathrm{X} 3600$

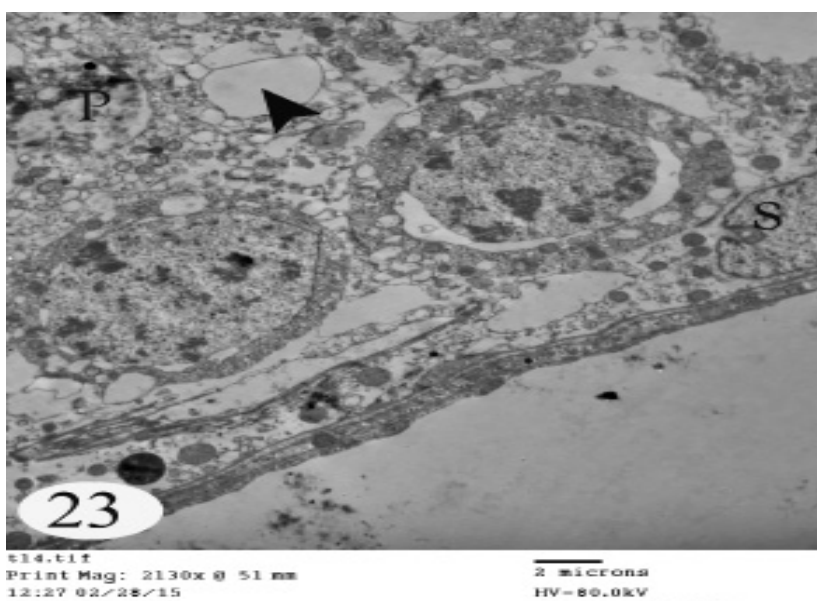

Fig. 23: An electron micrograph of albino rat testis (group 4) showing pachytene primary spermatocyte $(\mathrm{P})$ with degenerated cytoplasm that contains numerous vacuoles (arrow head). Notice the irregular Sertoli cell nucleus (S).

X3600

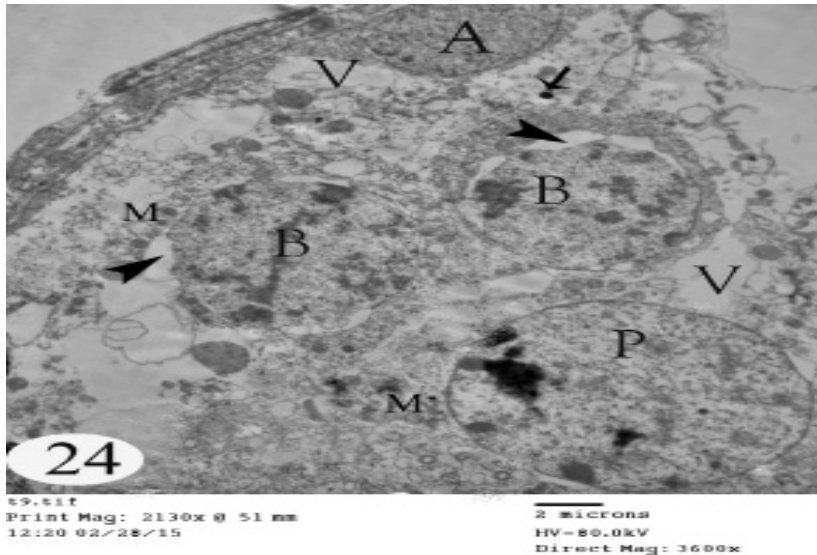

Fig. 24: An electron micrograph of albino rat testis (group 4) showing; type A spermatogonia (A), nuclei of type B spermatogonia (B) surrounded by empty space (arrow heads) and pachytene primary spermatocyte nucleus with heterochromatin (P). Notice the cytoplasm of the cells is scanty and contains vacuoles (V), lysosomes (arrow) and destructed mitochondria (M).

$\mathrm{X} 3600$ 


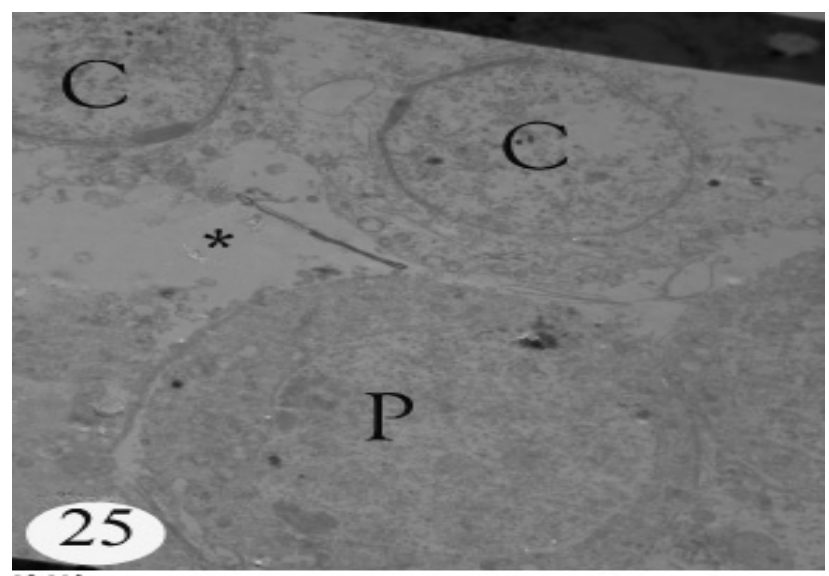

EAsit Mag: $2130 x$ o $51 \mathrm{~mm}$
Print Mag:
11:56 02/28/15

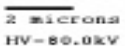

Hirert Mag = 3600x

Fig. 25: An electron micrograph of albino rat testis (group 4) showing pachyt ene primary spermatocyte (P) with heterochromatin nucleus and electron dense cytoplasm and cap phase spermatid (C) with scanty and degenerated cytoplasm (*).

$\mathrm{X} 3600$

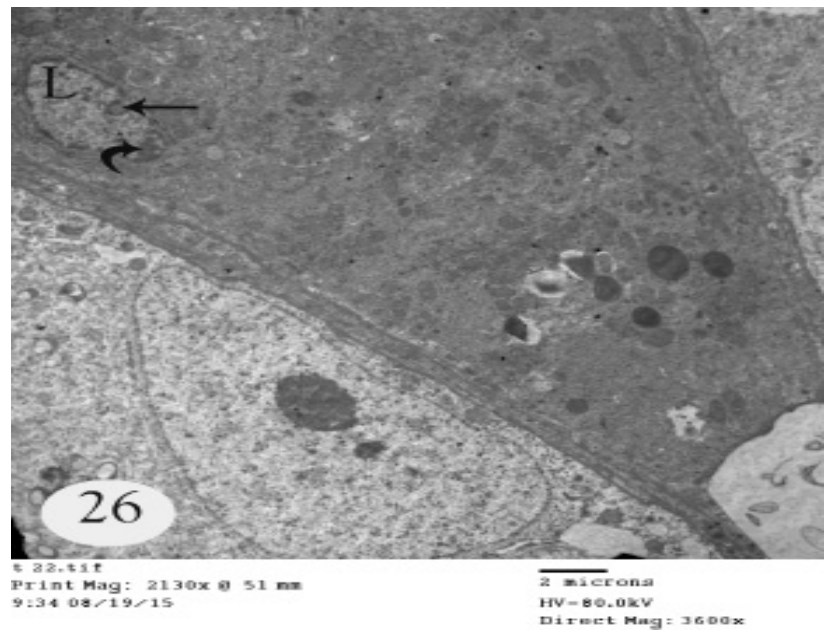

Fig. 26: An electron micrograph of albino rat testis (group 4) showing Leydig cell (L) with ill defined cellular membrane, irregular nuclear membrane (arrow) and marginal clump of heterochromatin (curved arrow).

X3600

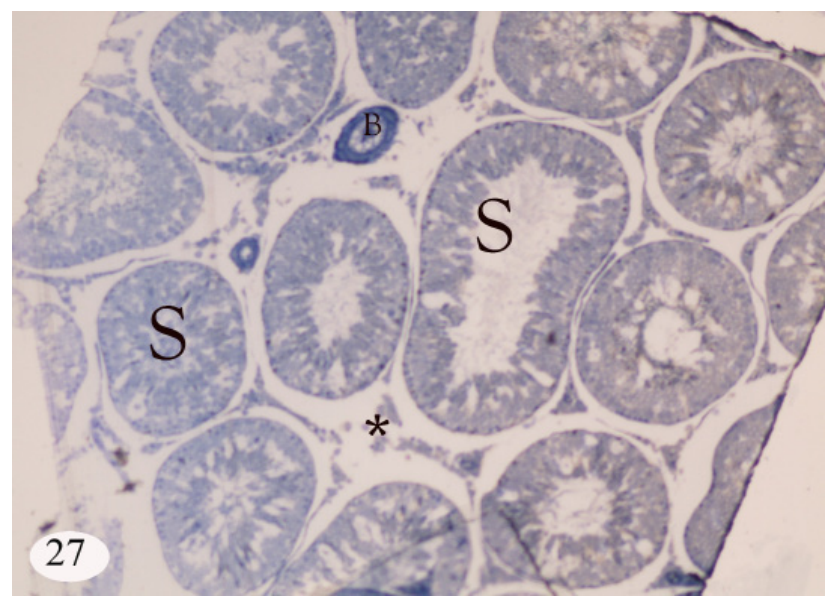

Fig. 27: A photomicrograph of a semithin section in the testis of albino rat (group 5) showing; seminiferous tubules that are empty of spermatozoa $(\mathrm{S})$ and degenerated interstitial tissue $(*)$ among the tubules. Notice the dilated thick walled blood vessel (B).

Toluidine blue, X100

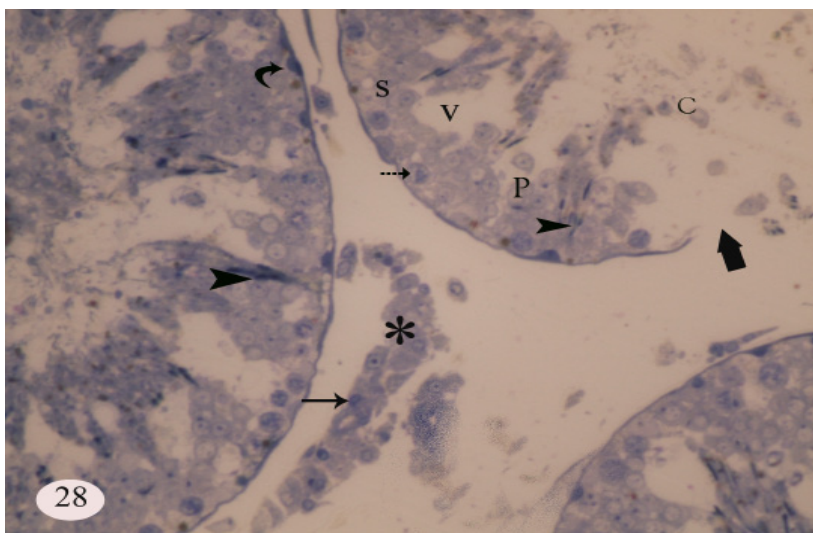

Fig. 28: A photomicrograph of a semithin section in the testis of albino rat (group 5) showing seminiferous tubules that are surrounded by a destructed basement membrane (thick arrow) and contain vacuoles (V). Type A spermatogonia (curved arrow), type B spermatogonia (broken arrow), pachytene primary spermatocytes (P), cap phase spermatids (C) and Sertoli cells (S) are degenerated. Abnormally located spermatozoa are located near the basement membrane (arrowheads). Notice the interstitial tissue $(*)$ with shrunken darkly stained Leydig cells (thin arrow). Toluidine blue, X400

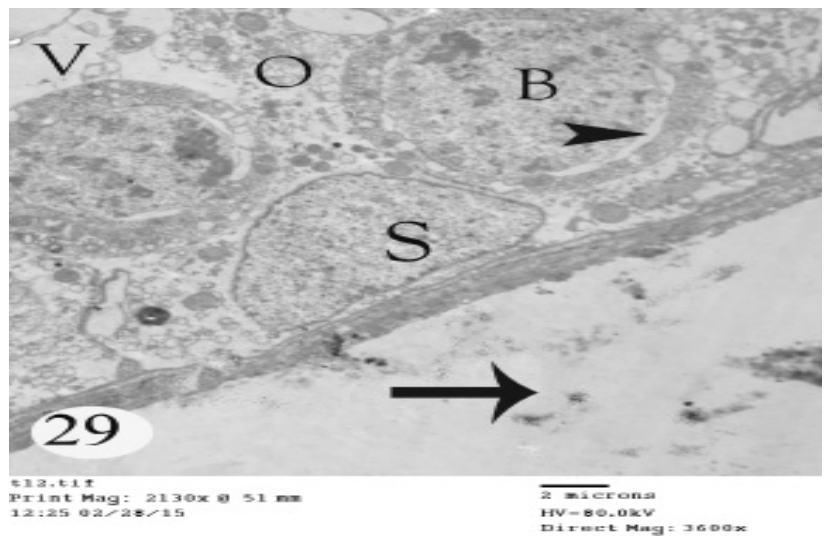

Fig. 29: An electron micrograph of albino rat testis (group 5) showing Sertoli cell nucleus (S) that is devoid of nucleolus. The cytoplasm is scanty $(\mathrm{O})$ and contains vacuoles (V). Type $\mathrm{B}$ spermatogonia nucleus $(\mathrm{B})$ is surrounded by an empty space (arrowhead). Notice the degenerated interstitial tissue (arrow).

X3600

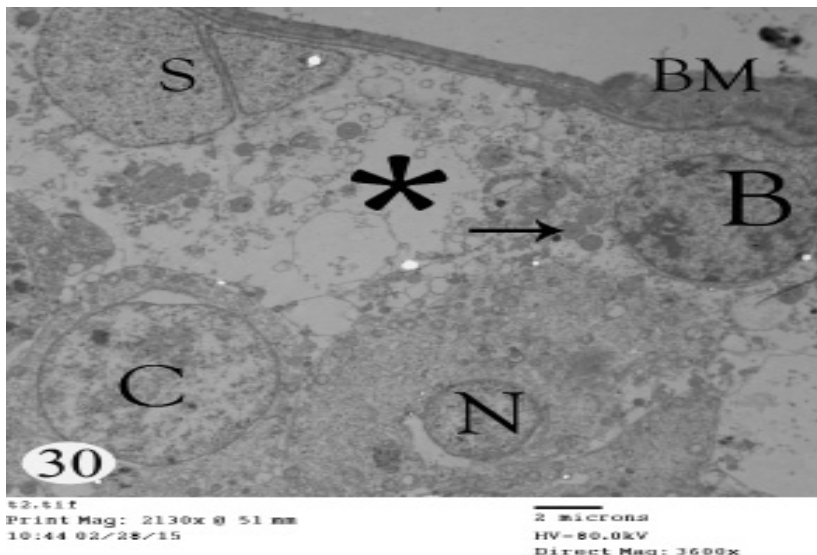

Fig. 30: An electron micrograph of albino rat testis (group 5) showing; deformed basement membrane $(\mathrm{BM})$, degenerated mitochondria (arrow) in type B spermatogonia (B) cytoplasm, shrunken pachytene primary spermatocyte nucleus $(\mathrm{N})$, cap phase spermatid nucleus with light acrosome (C) and broken Sertoli cell nucleus (S). Notice the degenerated Sertoli cell cytoplasm $(*)$. 


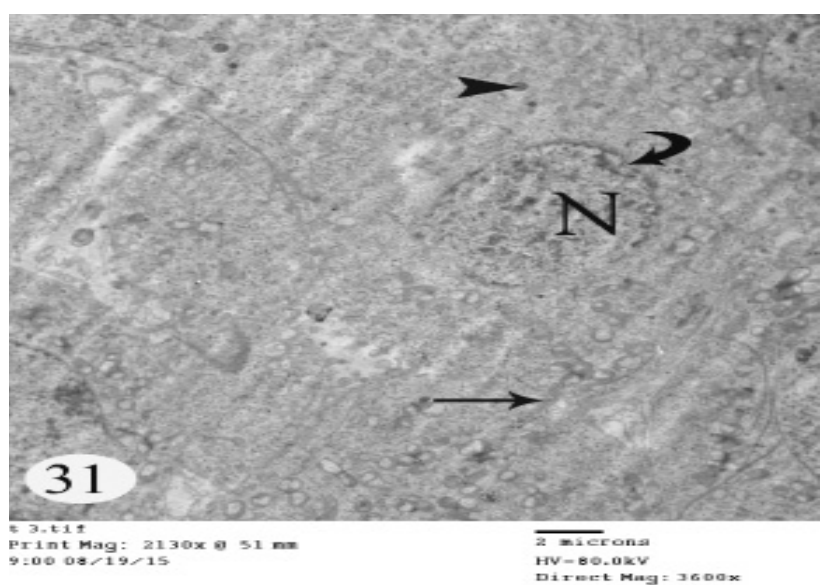

Fig. 31: An electron micrograph of a pachytene primary spermatocyte of albino rat testis (group 5) showing; heterochromatin nucleus $(\mathrm{N})$ with indentation and discontinuation of the nuclear membrane (curved arrow), a destructed cell membrane (arrow) and lysosome (arrow head) in the cytoplasm. X3600.

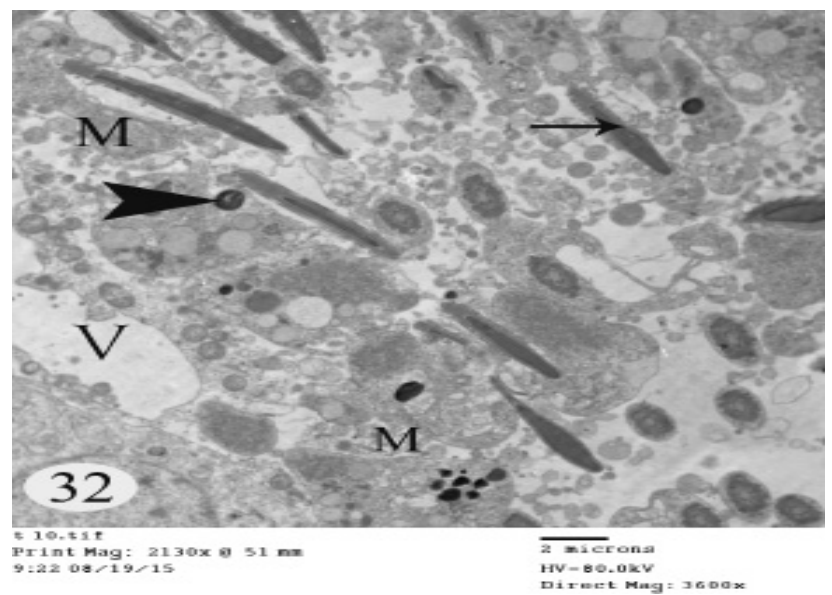

Fig. 32: An electron micrograph of albino rat testis (group 5) showing; abnormally located spermatozoa (arrow) among degenerated cells revealing vacuoles $(\mathrm{V})$, destructed mitochondria (M) and lysosomes (arrow head).

$\mathrm{X} 3600$

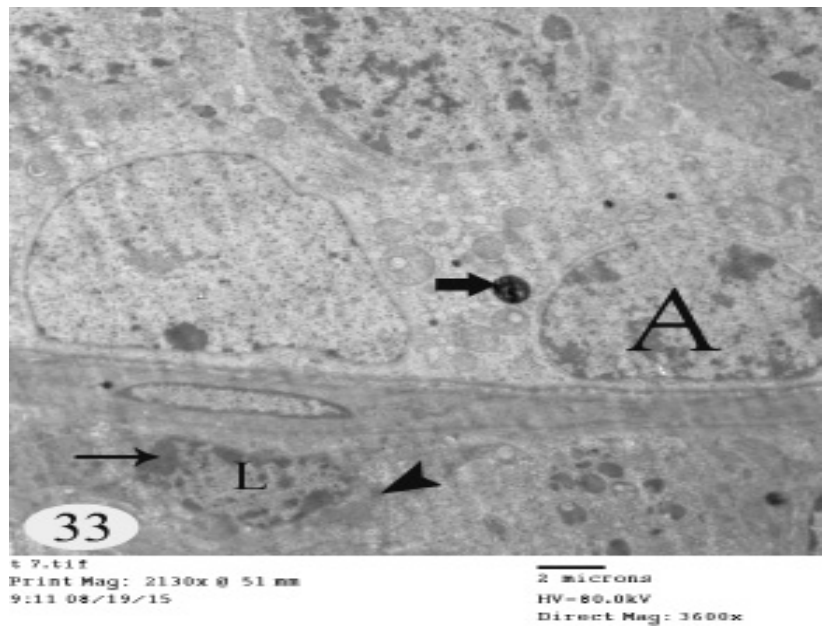

Fig. 33: An electron micrograph of albino rat testis (group 5) showing; Type A spermatogonia (A) cytoplasm that contains lipid droplets (thick arrow) and Leydig cell (L) with peripheral heterochromatin (arrow) and ill-defined cytoplasmic organelles (arrow head)

$\mathrm{X} 3600$

\section{DISCUSSION}

The most common disorders of the thyroid gland are hyperthyroidism and hypothyroidism ${ }^{[1]}$. Hyperthyroidism is a condition in which the thyroid gland secretes too much thyroid hormone and hypothyroidism results in insufficient amounts of thyroid hormone ${ }^{[9]}$. Both hyperthyroidism and hypothyroidism have been linked to cell damage ${ }^{[10-12]}$

Hyperthyroidism, or overactive thyroid, is most commonly a result of an autoimmune disease. Occasionally, it can result from a non-cancerous tumor in the thyroid gland or an infection of the thyroid gland ${ }^{[9]}$

By light microscope, the present study revealed degenerative changes in the seminiferous tubules of the hyperthyroidic animals. They were deformed with irregular basement membrane and luminal obliteration by residual spermatic bodies. Some tubules were surrounded by relatively thick myoid cells and lined by disorganized germ cells with empty spaces in between the cells. The type A spermatogonia had vacuolated cytoplasm. Type B spermatogonia appeared losing contact with the basement membrane. Cap phase spermatids appeared shrunken. Pachytene primary spermatocytes were more or less normal. Sertoli cell nucleus had no nucleolus and separated from the basement membrane. Additionally, there was an obvious interstitial oedema and the blood vessels were thick walled and dilated. Leydig cells appeared oval, shrunken and darkly stained. The electron microscopic examination of the basement membrane revealed irregular outline of the myoid cells nuclei. The nucleus of type A spermatogonia lost its oval shape. Type B spermatogonia had an electron dense cytoplasm. Pachytene primary spermatocytes and cap phase spermatids had irregular nuclei and degenerated cytoplasm showing destructed and swollen mitochondria and apparent decrease in the amount of ribosomes. Abnormally located sperms were observed. The Sertoli cells nuclei were irregular. The cytoplasm contained vacuoles, swollen mitochondria and large lipid droplets. The Leydig cells showed condensed peripheral chromatin material of the nuclei, destructed and displaced cell membrane, electron dense and swollen mitochondria.

These histological findings were confirmed by the statistical results; there was a significant decrease in the mean values of the testis mass of group 2 (hyperthyroidic group), in comparison to group 1 (control group)

These degenerative changes of the testis could be explained by the observations of Khdheir et al. ${ }^{[2]}$ and Makay et $a l^{[7]}$ who noticed that hyperthyrodic rats after L-thyroxine treatment ${ }^{[2]}$ and hyperthyrodic patients ${ }^{[7]}$, respectively, had increased malondialdehyde, glutathione and glutathione reductase while glutathione peroxidase decreased significantly compared to controls. They reported that in untreated rats and patients, hyperthyroidism 
increased the formation of reactive oxygen species (ROS) leading to oxidative damage to biomembrane lipids.

In fact, oxygen is needed to turn the components of food into energy that a body can use. Though this metabolic process is essential to staying alive, it also produces toxic and unstable byproducts called free radicals. Free radicals are produced when electrons are removed from an atom or molecule. This can lead to cell damage and abnormalities in cell growth ${ }^{[13]}$. Antioxidants can help to prevent cell damage by giving an electron to free radicals ${ }^{[14]}$.

Various data had shown that ROS were involved in the modulation of cell redox state and redox regulation of protein functions is now accepted as an additional regulatory mechanism of normal cell physiology ${ }^{[15]}$. Thus, ROS recently gained attention as important second messengers. However, excessive production of ROS might lead to oxidative stress, loss of cell function and cell death by apoptosis or necrosis ${ }^{[16]}$.

Similar seminiferous tubular degenerative findings were also observed by El-Gerbed ${ }^{[13]}$ after treatment with Methyl parathion. They attributed these findings to Methyl parathion passing blood-testes barrier and causing sperm DNA fragmentation.

The present study revealed that the testis of the hyperthyroidic animals treated with melatonin (group 3) showed attenuation of the degenerative changes caused by the hyperthyroidism. The seminiferous tubules were more or less like control group with patent lumina containing spermatozoa and interstitial tissue among the tubules. Type A spermatogonia, type B spermatogonia, pachytene primary spermatocytes, cap phase spermatids, Sertoli cells and Leydig cells were more or less like control group. In harmony with this result, there was a significant increase in the mean values of the mass of the testes of group 3 , in comparison to group 2 (hyperthyroidic group).

Melatonin is derived from the mood-enhancing neurotransmitter serotonin in the pineal gland. It is commonly used to cure sleep disorders and to adjust the sleep rhythm in people who work nightshifts. Melatonin is also a potent antioxidant and can be used to prevent oxidative stress $^{[17]}$.

These degenerative changes improvement were in accordance with that of hdheir et al. ${ }^{[2]}$ who observed that hyperthyroidic patients who received extra supplementation with melatonin attained euthyroidism and improvement in antioxidative status faster than patients treated with only carbimazole. They added that melatonin could be an effective adjuvant therapeutic tool to improve the clinical manifestation of this illness. Melatonin could interfere with the action of the peroxidase in one or both reactions; iodide oxidation and/or coupling reaction.
Our results were also parallel to those of Makay et $a l .{ }^{[7]}$ who observed that elatonin administration caused an inhibition of triiodothyronine and thyroxine, denoting the role of antioxidants which potentially inhibited the activation of oxidantmediated transcription factors, prevented the transcriptional activation of inflammatory cytokines and decreased the immune response by suppressing the oxidative stress. Ben Amara et al. ${ }^{[18]}$ confirmed that the antioxidants supplementation has been proved to have protective effects against oxidative damage by reinforcing cellular antioxidant defenses.

Moreover, Mogulkoc et al. ${ }^{[10]}$ and Soliman et al. ${ }^{[19]}$ indicated that hyperthyroidic associated-oxidative stress contributed to early cerebral, cardiac and hepatic complications. On addition of melatonin to anti-thyroid drugs, beneficial amelioration of these complications occurred. They attributed that to deiodinase 2 melatonin inhibition thus controlling local T3 concentrations.

Popov et al. ${ }^{[20]}$ stated that experimental thyrotoxicosis in rats was accompanied by the increase of serum alanine aminotransferase, aspartate aminotransferase and creatine phosphokinase-MB in liver, heart and blood. Whereas, exogenous melatonin was capable to reduce their levels leading to reduction of the intensity of lipid peroxidation and to act as an adaptogen regulating free radical homeostasis.

Furthermore, another mechanism of melatonin role in hyperthyroidic state improvement was explained by Johnson et al. ${ }^{[1]]}$ and Sejian and Swaroop ${ }^{[21]}$ who observed that melatonin administration could ameliorate the thermal stress condition and successfully modify the adrenal cortex functions.

Hypothyroidism is most often an autoimmune condition where smaller amounts of $\mathrm{T} 3$ and $\mathrm{T} 4$ are secreted by the underactive thyroid into the bloods stream decreasing the metabolism ${ }^{[22]}$.

In the present work carbimazole was used to induce hypothyroidism according to Zaidi et al..$^{[4]}$. Carbimazole is an anti-thyroid drug of thioamide group which acts by inhibiting the enzyme thyroid per-oxidase thereby blocking the iodination of thyroxine and preventing the formation of $\mathrm{T} 3$ and T4 in both mammals and birds ${ }^{[23]}$.

The present study revealed degenerative changes in the testis of the hyporthyroidic animals (group 4). The light microscopic examination revealed seminiferous tubules with lumen devoid of spermatozoa and obliterated seminiferous tubules lumina with debris. Additionally, some tubules were lined by disorganized germ cells with empty spaces in between the cells. Degenerated type A spermatogonia, type B spermatogonia, pachytene primary spermatocytes, cap phase spermatids and displaced Sertoli 
cells were observed. An oedematous interstitial tissue among the tubules revealing dilated blood vessel and shrunken darkly stained Leydig cells were observed. By electron microscopic examination, type A spermatogonia had vacuolated cytoplasm. The nuclei of type B spermatogonia were surrounded by empty space and the pachytene primary spermatocyte nuclei hadheterochromatin .The cytoplasm was scanty containing vacuoles, lysosomes and destructed mitochondria in some views. Electron dense cytoplasm was observed in others. Cap phase spermatids revealed scanty and degenerated cytoplasm. Sertoli cell cytoplasm was also scanty containing lysosomes, destructed mitochondria and vacuoles. Leydig cells with ill defined cellular membrane, irregular nuclear membrane and marginal clumps of heterochromatin were observed. The statistical results showed a significant decrease in the mean values of the mass of the testes of group 4, in comparison to group 1(control group).

Similar finding were recorded by Weng et al. ${ }^{[5]}$ who observed no spermatogenesis in the seminiferous tubules of the hypothyroidic quail when compared with the control one. They reported that hypothyroidism decreased the number and size of gonadotropes as same as the plasma concentration of $\mathrm{LH}$ and $\mathrm{FSH}$, implying that hypothyroidism probably caused gonadal dysfunction at the hypothalamus and pituitary levels.

Baltaci et $a .^{[24]}$ indicated that experimental hypothyroidism caused increased MDA levels, decreased GSH levels and caused lipid peroxidation in both kidney and testis. Similar finding were also recorded by Sarwar et $a l .{ }^{[25]}$ who observed that the experimentally induced hypothyroidism caused adrenal atrophy in mature as well as immature albino rats.

On the contrary, Hess et al. ${ }^{[26]}$ observed that, propyl thiouracil-induced neonatal hypothyroidism, increased testicular size, Sertoli, spermatocytes and round spermatids number and daily sperm production in the adult rat. The mean diameter of the Sertoli cell nucleolus showed a slight, but significant, decrease.

The discrepant data with the present results could be contributed to the different rats' age at the beginning of the experiment as they used neonatal rats.

The present study revealed that the testis of the hypothyroidic animals treated with melatonin (group 5) did not show any significant improvement. The light microscopic picture revealed seminiferous tubules that were empty of spermatozoa, were surrounded by a destructed basement membrane and contained vacuoles. Type A spermatogonia, type B spermatogonia, pachytene primary spermatocytes, cap phase spermatids and Sertoli cells were degenerated. Abnormally located spermatozoa were located near the basement membrane. Degenerated interstitial tissue among the tubules containing dilated thick walled blood vessel and shrunken darkly stained Leydig cells were noticed. By electron microscopic examination, the basement membrane was deformed. Type A spermatogonia cytoplasm contained lipid droplets. Type B spermatogonia cytoplasm contained degenerated mitochondria. The nucleus was surrounded by an empty space. The pachytene primary spermatocyte had shrunken nucleus in some views. In others, the nucleus contained heterochromatin with indentation and discontinuation of the nuclear membrane, a destructed cell membrane and lysosomes in the cytoplasm. Nucleus of cap phase spermatid with light acrosome was observed. Abnormally located spermatozoa among the degenerated cells revealing vacuoles, destructed mitochondria and lysosomes were observed. The Sertoli cell nuclei were devoid of nucleoli in some views and broken in others. The cytoplasm was scanty, containing vacuoles and degenerated. The interstitial tissue was degenerated. Leydig cells with peripheral heterochromatin and ill-defined cytoplasmic organelles were noticed. Moreover, there was a significant decrease in the mean values of the testis mass of group 5 in comparisonto the control one.

These results could be explained by Gordon et al. ${ }^{[27]}$, Ozturk et al. ${ }^{[28]}$, Panda et al. ${ }^{[29]}$ and Baltaci et al. ${ }^{[17]}$ who reported that melatonin had a thyroid suppressing action. They found that melatonin administration to rats increased basal thyrotropin-releasing hormone (TRH), radioactive thyroidal iodine uptake, thyroid gland size, total T4 content and T4:T3 ratio. The histological picture of the melatonin treated animals showed goitrogenic effect. They concluded that melatonin inhibited thyroid hormone synthesis or release. Accordingly melatonin supplements might downregulate the activity of the thyroid gland.

On the other hand, Thakkara et al. ${ }^{[9]}$ observed that, simultaneous melatonin administration effectively deprogramed the negative influence of neonatal hypothyroidism on immature follicles but not on mature follicles and body and ovarian weights. This different finding may be attributed to the different organ (ovary) they worked on.

\section{CONCLUSION}

Melatonin could protect against cell damage resulted by hyperthyroidism. However, it might down-regulate the activity of the thyroid gland and worsen the hypothyroidism state. So melatonin may be beneficial as a supplement for individuals with hyperthyroidism, but taking a melatonin supplement with hypothyroidism is an incorrect choice.

\section{CONFLICT OF INTEREST}

There are no conflicts of interest. 


\section{REFERENCES}

1. Dahmani-Said, S., Hamouli-Said, Z., Kamel, A. and Hadj-Bekkouche, F. (2013): Effects of thyroxine treatment during lactation on the testicular function of rats across different ages. Folia Histochemicaet Cytobiolog Ica. 51(2): 107-114.

2. Khdheir, F. A., Al- Sabbagh, M. and Al-Rubeiee, S. (2014):Anevaluation ofmelatoninas antioxidantinIraqi patients with hyperthyroidism. G.J.B.B. 3 (1): 51-55.

3. Alkalby, J. M. and Alzerjawi, S. J. (2013): Effect of propylthiouracil-induced hypothyroidism on reproductive effeciency of adult male rats. Bas. J. Vet. Res. 12(2):113-121.

4. Zaidi, T. M., Khan, A. A, Hasan, B. M. and Faruqi, A. N. (2004): Carbimazole induced thyroid histopathy in Albino rats during development. J. Anat. Soc. India. 53 (2):14-17.

5. Weng, Q., Saita, E., Watanabe, G., Takahashi, S., Sedqyar, M. Suzuki, A., Taneda S. and Taya, K. (2007): Effects of methimazole-induced hypothyroidism on adrenal and gonadal functions in male Japanese quail (Coturnix japonica). J. Reprod. Dev. 53:1335-1341.

6. Hassen, N. S. El Roubi, N. M. and Omara, E. A. (2007): Evaluation of the influence of each of melatonin and chromium against diabetesinduced alteration in the testis of Albino rats using Light and Electron Microscopies. Egyptian Journal of Hospital Medicine.27: 143-162.

7. Makay, B., Makay, O., Yenisey, C., Icoz, G., Ozgen, G., Unsal, E., Akyildiz, M. and Yetkin, E. (2009): The interaction of oxidative stress response with cytokines in the thyrotoxic rat: Is there a link? Hindawi Publishing Corporation Mediators of Inflammation.1-7.

8. Bozzola, J. J. and Russell, L. D. (1999): Electronemicroscopy: principles and techniques for biologists $.2^{\text {nd }}$ ed. Sudbury, M.A., Canada, UK, Library of Congress: Jones and Bartlett.

9. Thakkara, B. P., Zalaa, V. M. and Ramachandrana, A. V. (2011): Simultaneous melatonin administration effectively deprograms the negative influence of neonatal hypothyroidism on immature follicles but not on mature follicles and body and ovarian weights. J. Endocrinol. Metab.1 (5): 220-226.

10. Mogulkoc, R., Baltacia, A. K., Oztekinb, E., Aydina, L. and Sivrikayab, A. (2006): Melatonin prevents oxidant damage in various tissues of rats with hyperthyroidism. Life Sciences.79 (3): 311-315.

11. Johnson, E. O., Kamilaris, T. C., A Calogero., E., Gold, P. W. and Chrousos, G. P. (2005): Experimentallyinduced hyperthyroidism is associated with activation of the rat hypothalamic-pituitary-adrenal axis. European Journal of Endocrinology. 153: 177-185.

12. Sakr, S. A., Mahran, H. A. and Nofal, A. E. (2012): Effect of selenium on carbimazole-induced histopathological and histochemical alterations in prostate of Albino rats. American Journal of Medicine and Medical Sciences. 2(1): 5-11.

13. El-Gerbed, M. S. (2013): Histopathological and ultrastructural effects of methyl parathion on rat testis and protection by selenium. Journal of Applied Pharmaceutical Science.3: 53-63.

14. Sheweita, S. A., Tilmisany, A. M. and Al-Sawaf, H. (2005): Mechanisms of male infertility: role of antioxidants. Curr.Drug Metab. 6:495-501.

15. Veal, E.A., Day, A.M. and Morgan, B.A. (2007): Hydrogen peroxide sensing and signaling. Mol. Cell. 26: 1-14.

16. Nose, K. (2000): Role of reactive oxygen species in the regulation of physiological functions. Biol.Pharm .Bull. 23: 897-903.

17. Baltaci, A. K., Mogulkoc, R., Kul A., Bediz C. S. and Ugur, A. (2004): Opposite effects of zinc and melatonin on thyroid hormones in rat Toxicology. 195: 69-75.

18. Ben Amara, I., Troudi, A., Garoui, E., Hakim, A., Zeghal, K. M. and Najiba, Z. (2011): Protective effects of selenium on methimazole nephrotoxicity in adult rats and their offspring. Exp. Toxicol. Pathol. 30(10):1549-1560.

19. Soliman, G. Z., Bahgat, N. M. and Hamed, G. M. (2010): Effect of melatonin and/ or propylthiouracil on hyperthyroidic male rats. Journal of American Science.6 (10):904-914.

20. Popov, S. S., Pashkov, A. N., Popova, T. N., Zoloedov, V. I., Semenikhina, A. V. and Rakhmanova, T. I. (2008): The effect of melatonin on free radical homeostasis in rat tissues at thyrotoxicosis. Biochemistry (Moscow) Supplement Series B: Biomedical Chemistry. 2 (3): 302-305

21. Sejian, V. and Swaroop, R. (2010): Effects of melatonin on adrenal cortical functions of Indian 
goats under thermal stress. SAGE-Hindawi Access to Research.Veterinary Medicine International. 1-6.

22. Pereveen, K., Khan,N., Rafique,M., Samiullah,S. and Naqvi A. (2009): A histologic study of carbimazole-induced hyperpladsiaod adenohypophysis with protective role of thyroxine in male albino rats. JDUHS, 3(2):49-54.

23. Sinha, B. R., Chattopadhyay, R., DasGupta, M. and Chakraborty, S. (2014): Comparative study indicates methimazole induced chemical hypothyroidism causes inhibition of pineal gland karyomorphology in three different species of animals. International Journal of Pure and Applied Zoology. 2: 84-94.

24. Baltaci,A.K.,Mogulkoc, R.,Ayyildiz,M.,Kafali,E. and Koyuncuoglu, T. (2014): Lipid peroxidation in kidney and testis tissues in experimental hypothyroidism: the role of zinc. BratislLek. Listy. 115(8):498-501.

25. Sarwar, G., Parveen, S. U. and Siddiqui, M. A. (2008): comparison of the effects of experimentally induced hypothyroidism in adrenal glands morphology in pre and postnatally treated albino rats. Pakistan Journal of Pharmacology. 25: 13-18.

26. Hess, R. A., Cooke, P. S., Bunick, D. and Kirby, J. D. (1993): Adult testicular enlargement induced by neonatal hypothyroidism is accompanied by increased Sertoliandgermcellnumbers.Endo.132(6):2607-2613

27. Gordon, J., Morley, J. E. and Hershman, J. M. (1988): Melatonin and the thyroid.Acta Endocrinol.119: 240-244.

28. Ozturk, G., Coskun, S., Erbas, D. and Hasanoglu, E., (2000): The effect of melatonin on liver superoxide dismutase activity serum nitrate and thyroid hormone levels. Jpn. J. Physiol. 50:149- 153.

29. Panda,J.N.,Turner,C.W.andPowell,M.(2000):Therole of melatonin in the regulation of thyrotrophin secretion. The Japanese Journal of Physiology. 50(1):149-153. 


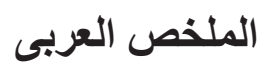

\title{
التأثيرات الناتجة عن الاعطاء المتزامن لمادة الميلاتونين على الخصية فى الفئران

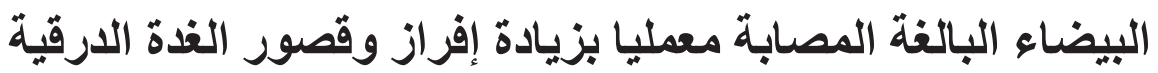

\author{
هاله زين العابدين محمد ورينيه رفعت بشرى \\ قسم التشريح الآدمى والأجنة ـ كلية الطب - جامعة أسيوط ـ أسيوط ـ مصر
}

المقدمة: زيادة إفراز وقصور الغدة الدرقية من أكثر الاضطر ابات شيو عاو كلاهما يؤدى إلى تلف الخلية.

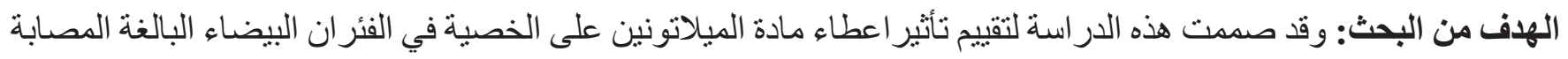

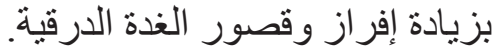

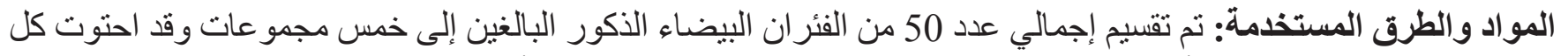

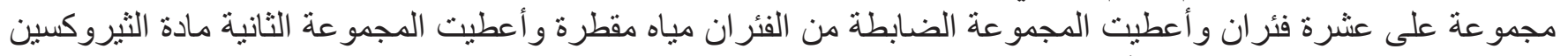

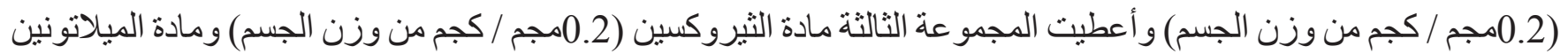

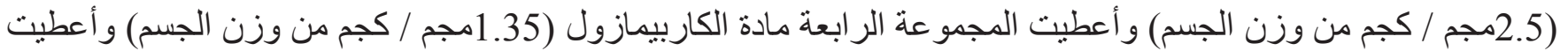

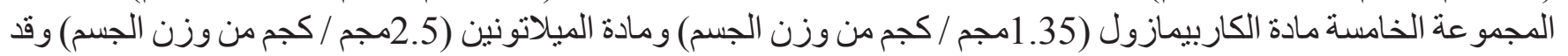

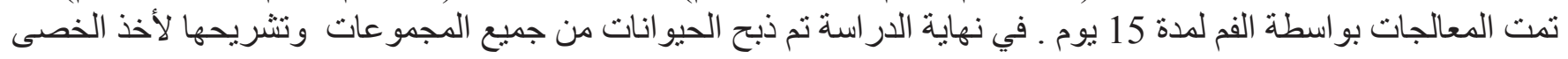

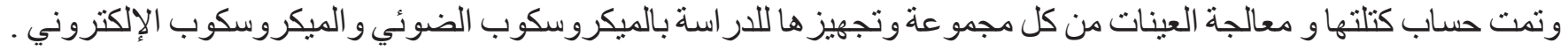

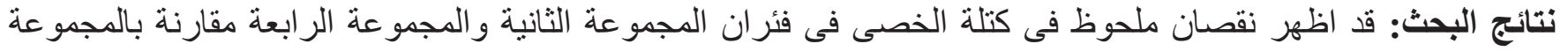

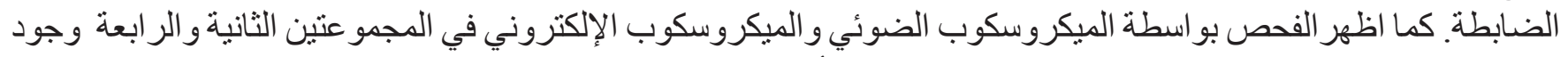

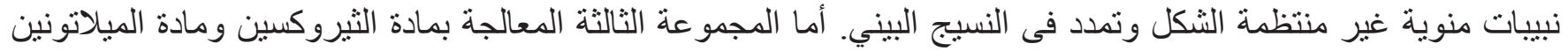

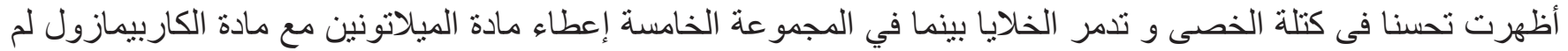

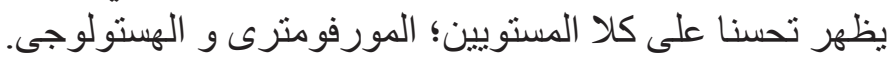

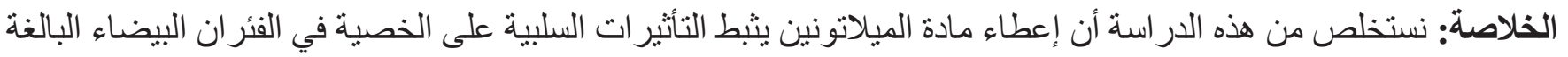
الناتجة عن زيادة إفر از وليس قصور الغدة الغدة الدرقية. 